\title{
GCU
}

Glasgow Caledonian

University

University for the Common Good

\section{Exploring emotional intelligence and conflict management styles in Dominican Republic construction industry}

Lawani, Kenneth; Arias Abad, Luis Alfredo ; Craig, Nigel; Hare, Billy; Cameron, lain

Published in:

Journal of Engineering, Design and Technology

DOI:

10.1108/JEDT-09-2021-0485

Publication date:

2022

Document Version

Author accepted manuscript

Link to publication in ResearchOnline

Citation for published version (Harvard):

Lawani, K, Arias Abad, LA, Craig, N, Hare, B \& Cameron, I 2022, 'Exploring emotional intelligence and conflict management styles in Dominican Republic construction industry', Journal of Engineering, Design and Technology. https://doi.org/10.1108/JEDT-09-2021-0485

\section{General rights}

Copyright and moral rights for the publications made accessible in the public portal are retained by the authors and/or other copyright owners and it is a condition of accessing publications that users recognise and abide by the legal requirements associated with these rights.

Take down policy

If you believe that this document breaches copyright please view our takedown policy at https://edshare.gcu.ac.uk/id/eprint/5179 for details of how to contact us. 


\title{
Exploring emotional intelligence and conflict management styles in Dominican Republic construction industry
}

\begin{abstract}
Purpose - Emotional intelligence (EI) and conflict management (CM) are essential skills for construction managers towards achieving organizational effectiveness. It is believed that an individual's EI level is a predictor of the preferred CM styles. This study explored the relationships between EI levels, preferred CM styles and demographic factors in the construction sector of the Dominican Republic.
\end{abstract}

Design/methodology/approach - The Emotional Intelligence Levels (EIL) and Conflict Management Styles (CMS) of a sample of Civil Engineers in managerial positions were evaluated using the Emotional Intelligence Appraisal (EIA) and Rahim Organizational Conflict Inventory-II (ROCI-II) self-assessment tools.

Findings - There was a strong positive correlation between the rated EIL and the scores of collaboration and compromise styles i.e. participants with higher EIL have stronger fit within the collaboration and compromise styles of managing conflicts. For participants with lower EIL, collaboration and compromise styles were also top preferences, but with no statistical significance. Significant relationships existed between gender, collaboration and compromise styles, and between work experience and collaboration style, with no significant relationship between demographics and EIL.

Practical implications - The construction industry need innovative construction managers whose CM styles and EIL are compatible with the culture and overall organizational objectives.

Originality/value - This is the first study appraising the emotional intelligence and conflict management styles of civil engineers working in Dominican Republic construction industry.

Keywords - Emotional intelligence, Conflict management, Dominican Republic, Construction

Paper type - Research paper

\section{INTRODUCTION}

The construction industry is constantly evolving in terms of successfully managing projects and there are emerging challenges regarding effectively managing the personnel, the construction health and safety, and managing the project outcomes in terms of time, cost and quality. Within the workplace, it is believed that emotional intelligence (EI) can potentially help in conflict resolution, build a collaborative culture, motivate other workers and help create psychological safety within working teams (Kukah et al., 2021; Sunindijo \& Maghrebi 2020; Montenegro et al., 2021). The concept of EI comprises a set of personal and social competencies for perceiving, understanding, using and managing emotions to interact and influencing others and ones' own emotions. EI has become widespread within organisations because of its ability to impact the individual and the performance of others within their organisations (Cherniss \& Goleman, 2001; Hasson, 2015). The ability to resolve or manage conflicts is one significant competence related to EI (Cherniss \& Goleman, 2001). Rahim (2002) defines conflict as an interactive process manifested in incompatibility, disagreements, or dissonance within or between social entities. In most construction projects, issues of incompatibility, disagreements and dissonance are common occurrence and personnel in 
managerial positions are in a position or responsible for addressing some of these issues for the personal and collective success and for better work-related performance (Bollen, et al., 2016). The ever-increasing complexity of construction projects and the number of duty holders involved means that conflicts are even more likely to arise. This suggests that the ability to effectively manage and resolve conflict is an important skill for project managers toward achieving positive outcomes for the organisation and the satisfaction of all personnel (Akiner, 2014).

Therefore, the ability to manage construction project-related conflicts is inevitable and the application of strategies to resolve such conflicts cannot be underestimated. Conflict management styles (CMS) is regarded as the preferred conduct employed by individuals when dealing with conflict (Moberg, 2001; Wang et al., 2021; Chandolia \& Anastasiou 2020). Rahim et al., (2001) identified and broadly defined five CMS as determined by the low or high degree of assertiveness and cooperativeness used in dealing with the conflict. Studies have identified that when conflict in organisations are not adequately managed, it can lead to destructive behaviours, lack of trust amongst workers, impact safety practices and reduce productivity (Vaux \& Kirk, 2018; Akiner, 2014; Lawani et al., 2019; Manu et al., 2015). EI is often considered as an important predictor of certain CMS and the preferred CMS are mostly predetermined by individual characteristics (Shih \& Susanto, 2010; Antonioni, 1998). It is also suggested that there are relationships between emotional intelligence levels (EIL), conflict management styles (CMS), culture clusters and demographic factors (Chen, et al., 2019; Gunkel, et al., 2016). However, there is no study that has addressed these relationships in the Dominican Republic construction industry. Therefore, this study contributes to the understanding of EI and CMS in the context of the Dominican Republic (DR), by evaluating if there are significant relationships between these two components and between demographic variables. This involves exploring the EIL and demographic factors and the preferred CMS of Civil Engineers in the construction industry of the Dominican Republic. Based on this premise, this study identifies the most common EIL and the preferred CMS among the civil engineers in Dominican Republic; evaluate the relationship between EIL and demographic factors such as gender, age, and years of work experience; investigate the relationship between preferred CMS and demographic factors such as gender, age, and years of work experience; and finally, appraise the relationship between EIL and preferred CMS.

\section{LITERATURE REVIEW}

\section{Emotional Intelligence (EI)}

Salovey and Mayer (1990) defined emotional intelligence (EI) as a type of social intelligence that comprises the capacity to oversee your own emotions and that of others, to differentiate among them, and to use the information to manage your thinking and behaviour. Subsequent study by Mayer \& Salovey (1997) reconceptualised the definition as the ability to perceive and integrate emotions to enable thinking, understanding and regulating emotions that stimulate personal growth. Bar-On (1997) furthermore identified emotional quotient (EQ) as an indicative measure for emotional intelligence. Bar-On described EI as knowing yourself and others, relating with individuals, and adjusting to the surrounding environment towards becoming more effective in dealing with the difficulties. The interest of researchers in understanding EI has significantly increased in other fields and this has led to extensive investigation indicating that organisational success is not only attributed to intellectual abilities 
(analytical), but also, to emotions related to skills (Côté \& Miners, 2006). There are different train of thought on the issue of EI as indicated by these studies; treated as an ability (Mayer \& Salovey, 1997), and as a trait or mixed model of personality attributes and abilities (Goleman, 2009a; Goleman, 2009b; Bar-On \& Parker, 2000). The work of Cherniss \& Goleman (2001) identified four critical domains (Self-Awareness; Self-Management; Social Awareness; and Relationship Management) and 20 competencies that are considered as the framework for EI. These domains are also reflected in the works of Sunindijo \& Maghrebi (2020) and Moradi et al., (2020).

Self-Awareness involves recognising one's own feelings, inner conditions, inclinations, possessions, perceptions, and an understanding of how all these may impact performance (Goleman, 2009b). Individuals with a high level of emotional self-awareness have an understanding of their feelings, why, and how it can positively or negatively impact on their goals (Goleman, et al., 2017). Self-Management is the ability to manage emotions and moods towards preventing upsetting attitudes and impulsive reactions (Cherniss \& Goleman, 2001). Self-management is a crucial aspect within the domains of EI because it determines the individual's internal mechanisms around the issues of self-control and provokes a productive interpersonal relationship (Ikpesu, 2017). Social Awareness involves correctly interpreting other people's feelings, and being able to differentiate between authentic and fake emotional expressions (Cherniss \& Goleman, 2001). The capability of perceiving the emotions of other people is essential for personnel in managerial positions because it helps them to collect valuable information about attitudes, goals and intentions (Côté, 2017). Relationship Management is the ability to influence the emotions of other people in the pursuit of a desired action or behaviour (Cherniss \& Goleman, 2001). Relationship management involves connecting with other people empathetically with a well-developed social skill and compassion whilst using emotional awareness to lead such feelings and conducts (Torubelli \& Adeoye, 2011; Meng 2012).

\section{Conflict Management}

From an organisational perspective, conflict is a social phenomenon that arise due to disagreements between individuals or groups with personal or collective objectives that interact with each other within a common environment (Proksch, 2016; Maiti \& Choi, 2021). Conflicts in organisations can be categorized into different types. Relationship conflict refers to interpersonal emotional aspects (e.g. conflict of beliefs), while cognitive conflict arises from disputes about objectives (e.g. conflict of interest) (Khan, et al., 2016; Whitfield, 2012). On the other hand, personal conflict indicates personality traits of workers (e.g. conflicting personalities), while organisational conflict results from characteristics and processes which is a reflection of the organisation (e.g. organisational structure and hierarchical conflict) (Spaho, 2013; Subramoniam, 2004). Although the occurrence of conflicts is inevitable, individuals tend to develop skills to deal with such conflicts (Whitfield, 2012). Conflict management refers to the competence of building and using rational, emotional, and social abilities to achieve productive outcomes from conflict whilst reducing the probability of escalation or damage (Runde \& Flanagan, 2010). Conflict management is considered as an interactive process for transforming destructive emotional states into constructive attitudes by providing a resolution to the conflict (Elgoibar, et al., 2016). The resolution method is commonly known as conflict management styles (CMS), which refers to the actions or strategies adopted to resolve a conflict (Moberg, 2001; Maiti \& Choi, 2021). 
The common conflict management styles are avoidance, competition, compromise, accommodation, and collaboration (Rahim, 1983a). Avoidance is an unassertive and uncooperative conflict management style that is characterized by low concern with personal goals and relationships (Northouse, 2018; Tsai \& Chi, 2009). Avoidance may be beneficial when a concern is of little significance or when the probable outcome from the conflict would be too damaging (Rhoden, 2016; Northouse, 2018). Competition is a highly assertive but uncooperative conflict management style that has high concern with personal goals but low concern with relationships (Northouse, 2018; Tsai \& Chi, 2009). The main focus of competition is on winning or achieving the goals regardless of the needs of the other parties and this is synonymous with forcing to win one's position or imposing self-interest (Rahim, et al., 2001). Compromise is considered as the moderate assertive and cooperative conflict management style, and it raises a midpoint in the negotiation where both parties lose something to win other things (Northouse, 2018; Rahim, et al., 2001). Accommodation is an unassertive but cooperative conflict management style that emphasises low concern for personal goals but high concern for relationships (Tsai \& Chi, 2009; Northouse, 2018). Accommodation style is deemed to be productive when one party feels the problem is more critical for the other than themselves. The emphasis is on whether keeping the peace in the relationship without confrontation is the most important issue for the person accommodating (Gonçalves, et al., 2016). Collaboration style of conflict management is a highly assertive and cooperative style that focuses on great concern for personal goals and relationships (Northouse, 2018; Tsai \& Chi, 2009). The outcome of collaboration style is widely considered as positive because both parties involved achieve a win-win solution, the interaction is rewarding, partnerships are improved, and the long-term cost-effectiveness of agreed solutions are normally greater (Northouse, 2018; Loosemore, et al., 2000; Barbuto, et al., 2010). Therefore, collaboration is considered as the most recommended style of conflict management according to different authors (Loosemore, et al., 2000; Barbuto, et al., 2010; Northouse, 2018). Collaboration style is also regarded as the best form of workforce engagement where the management and the workforce address issues of planning, management, monitoring and coordination of a project to ensure that issues of health and safety takes precedence and are adequately resolved (Lawani et al., 2019).

\section{Conflict Management Styles (CMS) measurement}

Research on conflict resolution strategies is popular in several fields and contexts including management (Rahim, 1983a). It focuses on the capacity to assess the preferences of individuals based on the various styles of conflict resolution. The earliest models adopted for measuring preferred conflict management styles began by focusing on two or three styles. Subsequently, it moved to four, and finally to five, with the five-style being the most widely adopted in present models (Kessler, 2013). The recognized instruments for measuring CMS are divided into three scaling procedure: Force-Choice, Likert Scaling, and Best-Worst Scaling (Daly, et al., 2010). These assessments are based on questionnaires that are available in both printed and digital versions (Kessler, 2013), and the responses from participants should provide same results regarding the preferred styles of conflict management. For this study, the Likert scaling procedure is adopted in line with the widely accepted and validated Rahim Organizational Conflict Inventory-II (ROCI-II) instrument (Rahim, 1983b). The Rahim Organizational Conflict Inventory-II (ROCI-II) instrument is considered to have good psychometric properties, and it is widely adopted in academic surveys (Kessler, 2013). 


\section{Emotional Intelligence Levels (EIL), Conflict Management Styles (CMS) \& demographics}

The construction industry is characterized by its complexity, diversity of resources and a nonstandardized model of production (Sears, 2015). However, the people that are directly involved in the construction process are deemed to be the most important assets of any construction organisation (Robbins \& Coulter, 2016). The industry is an important economic sector for all countries and the engagement of construction employees and the ability to manage their behaviours is fundamental to the success for better work-related performance and improved safety. Construction workers constitute the base of every construction project activities and the ability to resolve conflicts through workforce engagement, promote trust within the workplace and manage safe behaviour at work is essential for improved safety performance and productivity (Lawani et al., 2019). Furthermore, study shows that the construction industry in the Dominican Republic grapples with problems of unregulated and harmful alcohol consumption by workers and this directly have an impact on workplace safety (Lawani et al., 2020), which may potentially hinder the ability to resolve workplace and work-based conflicts. Issues involving alcohol misuse can have detrimental impact on workforce engagement and work-related accidents irrespective of geographical location of workers (Lawani et al., 2019; Lawani et al., 2020). Therefore, work-related pressures, extended and long working hours, macho attitude, long commute to job sites, meeting tight deadlines, lack of job control or autonomy, excessive and conflicting demands, inadequate safety training, poor working conditions, and the temporary nature of projects and employment could have an impact on construction worker's ability to resolve conflicts within the workplace.

That is why an assessment of EI becomes an important and recommended feature for improving performance in construction projects (Pryke, et al., 2015); and the advantages of assessing EI in construction towards enhancing project effectiveness has been alluded to by Love et al. (2011). Based on the lack of existing study in the Dominican Republic construction sector, the inter-relationship between emotional intelligence levels and the issue of demography being addressed in this paper are considered timely and relevant. Despite the wide research interest regarding EI and management in the last decade, there is a low number of empirical studies on EI in construction which addresses issues of identity and culture (Saini \& Soni, 2016; Lawani \& Moore, 2021); very few linking EI levels and demographics in the construction industry (Mo \& Dainty, 2007); and none in the context of the Dominican Republic. The only indicator could be due to the cultural perception that EI is a sign of weakness in a male-dominated industry as suggested by Loosemore \& Galea (2008). Regardless of the industry, existing studies have shown differences between the levels of emotional intelligence and demographic variables. For example, demographic variables such as gender, age and work experience have been widely analysed and studies found that women have higher EI levels compared to men (Petrides, et al., 2004; Siegling, et al., 2014); older workers have higher levels of EI compared to their younger colleagues (Bar-On, 1997; Mayer, et al., 1999; Van Rooy, et al., 2005), and more experienced workers have more chance to improve their emotional intelligence competencies (Kaifi \& Noori, 2010; Bar-On, 1997). These findings affirm the hypothesis that females are more emotionally intelligent than males and that emotional intelligence increases with age and work experience (Bar-On, 1997; Mayer, et al., 1999; Petrides, et al., 2004).

Conflicts in construction projects which are often common are unavoidable because of the participation of diverse stakeholders with different plans and expectations (Ofori, 2013), and 
these can be associated to the particular history, character, culture, beliefs and behaviours of the parties involved (Randeree \& Faramawy, 2011; Lawani \& Moore, 2021). Consequently, the ability to manage conflicts is a major component of project management towards achieving project success (Wu, et al., 2017) and improved safety performance. One of the frameworks used in resolving conflicts is by adopting diverse conflict management styles (Rahim, 2002). However, findings on conflict management are not consistent in terms of the preferred techniques to handle and resolve conflicts in different countries, and this could be moderated by the differences in culture (Lawani \& Moore, 2021; Gunkel, et al., 2016; Vu \& Carmichael, 2009).

\section{Relationship between Emotional Intelligence Levels (EIL) and Conflict Management Styles (CMS)}

There are existing studies that have explored the relationship between EIL and CMS components in the context of the construction industry. Jordan and Troth (2004) stated that EI play an essential role in conflict management, suggesting that higher levels of EI may encourage collaborative behaviours towards finding innovative and creative solutions that satisfy the needs of the parties involved. However, lower levels of EI tend to use competition and avoidance style to manage conflicts (Goleman, 2009a). Sunindijo and Hadikusumo (2014) revealed that construction professionals with high EI often use accommodation-style to manage conflicts, and that they are also comfortable in using collaboration style, influenced by their collectivist culture. Conflict management styles have also been related to some of the EI components when dealing with subordinates, peers, and superiors. Chen et al. (2019) conducted a study with employees across different levels within organisations in China and showed that the preferred CMS vary according to the party they are interacting with. For example, managers in confrontation with their peers and superiors appear to follow the style of avoidance, collaboration and accommodation while scoring high levels on self-management and relationship management.

Jordan and Troth (2002) found that the effectiveness of conflict management relies on the individual's level of EI; and it is less effective in those with low levels of EI. Therefore, since collaboration and compromise are considered as more appropriate in producing functional outcomes, individuals with higher levels of EI tend to lean towards collaboration and compromise styles (Gross \& Guerrero, 2000). Although some researchers suggest that collaboration is the most effective conflict management style due to its win-win solution, each style is adaptable to fit specific situations and context (Sunindijo \& Hadikusumo, 2014). Even though the significance of EI and the use of the appropriate CM for organisational effectiveness is widely acknowledged, there are no literature that depicts such interaction or relationship between EIL and CMS in the context of the Dominican Republic construction industry.

\section{STUDY DESIGN}

\section{Theory development}

This study reviewed literature and focused on theory testing by adopting the deductive approach to theory development (Saunders, et al., 2019). The deductive approach is functional when the conclusion is reasonably derived from a set of premises drawn from theory, in which the conclusion could turn out to be true when all the premises are proven to be true or vice versa (Blaikie \& Priest, 2019). The requirement is to establish a hypothesis that is subjected to 
rigorous examination by means of a set of propositions that provides the basis for interpretation. This requirement also enables events to be predicted based on their occurrence, thus enabling them to be regulated (Blaikie \& Priest, 2019). This study applied a structured methodology, such that the concepts were operationalised to allow the data to be quantitatively measured whilst ensuring for replication, validity and reliability (Saunders, et al., 2019). Table 1 presents the research questions and hypothesis for this study.

This study adopted the mono-method quantitative approach by utilising a single data collection technique. The data was collected using a standardized survey questionnaire with precise questions deployed in the same way for each participant. Furthermore, the data was collected by means of a survey strategy to determine probable justifications for specific links between the variables and their relationships (Saunders, et al., 2019). The study explored relationships between variables that were numerically measured and analysed with standard statistical procedure (Saunders, et al., 2019). The study adopted the simple random sampling technique, remaining distant and independent from the respondents to avoid influencing the statistics.

Table 1 - Research questions and hypotheses

\begin{tabular}{|c|c|c|}
\hline Item & Research Question & Hypothesis \\
\hline RQ1 & $\begin{array}{l}\text { What are the most common levels of } \\
\text { emotional intelligence? }\end{array}$ & $\begin{array}{l}\text { Most participants possess a high level or moderate level } \\
\text { of emotional intelligence. }\end{array}$ \\
\hline RQ2 & $\begin{array}{l}\text { What are the most preferred conflict } \\
\text { management styles? }\end{array}$ & $\begin{array}{l}\text { Most participants prefer collaboration and compromise } \\
\text { styles for managing conflicts. }\end{array}$ \\
\hline RQ3 & $\begin{array}{l}\text { What is the relationship between } \\
\text { emotional intelligence levels and } \\
\text { demographic factors like gender, age, and } \\
\text { years of work experience? }\end{array}$ & $\begin{array}{l}\text { There are significant relationship between emotional } \\
\text { intelligence levels and the demographic factors like } \\
\text { gender, age, and years of work experience. }\end{array}$ \\
\hline RQ4 & $\begin{array}{l}\text { What is the relationship between preferred } \\
\text { conflict management styles and } \\
\text { demographic factors like gender, age, and } \\
\text { years of work experience? }\end{array}$ & $\begin{array}{l}\text { There are no significant relationship between the } \\
\text { preferred conflict management styles and the gender of } \\
\text { the participants, but there are significant relationships } \\
\text { with age and years of work experience. }\end{array}$ \\
\hline RQ5 & $\begin{array}{l}\text { What is the relationship between } \\
\text { emotional intelligence levels and preferred } \\
\text { conflict management styles? }\end{array}$ & $\begin{array}{l}\text { Participants with higher EQ prefer collaboration and } \\
\text { compromise styles for managing conflicts, whilst } \\
\text { participants with lower EQ prefer accommodation and } \\
\text { avoidance styles. }\end{array}$ \\
\hline
\end{tabular}

\section{Data collection}

The data collection focused on Civil Engineers practising in the Dominican Republic construction industry. The target population was specifically Civil Engineers within managerial positions in different construction organisations. These Civil Engineers $(N=19,553)$ are registered in the Dominican Association of Engineers, Architects and Surveyors (CODIA) (CODIA, 2020). To get the sampling frame organised, the participants were randomly selected from the CODIA records which is a reliable and accurate database for the professionals in the Dominican Republic. A total of 76 Civil Engineers were contacted to participate in the study, and 64 consented. However, 49 participants returned the fully completed questionnaires giving the study a response rate of $76.56 \%$. The participants (males and females) were within the age bracket of 24 to 44 years with 1 to 17 years of work experience in the construction industry. The lowest qualification was a bachelor's degree in Civil Engineering, while some of the respondents have postgraduate degrees. The data was categorised based on gender (male and female), while the age range and years of work experience of the participants were grouped 
into three groups $(24-30 ; 31-37 ; 38-44)$ and $(1-5 ; 6-11 ; 12-17)$, see Table 2 for each of these variables. The data collection strategy adopted the use of self-reported questionnaires. The participants were required to complete the Emotional Intelligence Appraisal (EIA) and Rahim Organizational Conflict Inventory-II (ROCI-II) questionnaires, as well as completing some demographic information such as gender, age, and years of work experience. This information was essential to facilitate linking these variables with the results of the EIL and CMS test.

Table 2 - Gender, age, work experience, education, management position, and organisational size demography

\begin{tabular}{llll}
\hline Variables & & Participants & Percentage (\%) \\
\hline Gender & Sex & & \\
& Male & 36 & $73.47 \%$ \\
Age & Female & 13 & $26.53 \%$ \\
Years & & \\
& $24-30$ & 5 & $10.20 \%$ \\
Work Experience & $31-37$ & 36 & $73.47 \%$ \\
& $38-44$ & 8 & $16.33 \%$ \\
Qualification & Years & & \\
& $1-5$ & 7 & $14.29 \%$ \\
& $6-11$ & 32 & $65.31 \%$ \\
Management Position & $12-17$ & 10 & $20.41 \%$ \\
& Degree & & \\
& Bachelors & 17 & $34.69 \%$ \\
& Masters & 31 & $63.27 \%$ \\
Organisation & Doctorate & 1 & $2.04 \%$ \\
& Level & & $14.29 \%$ \\
& High & 7 & $75.51 \%$ \\
& Middle & 37 & $10.20 \%$ \\
& Low & 5 & $44.90 \%$ \\
& Size & & $32.65 \%$ \\
& Large & 22 & $22.45 \%$ \\
\hline
\end{tabular}

\section{Emotional Intelligence Appraisal (EIA)}

The Emotional Intelligence Appraisal is a mixed EI measure that is useful in developing a simple and accurate test of emotional intelligence that is applicable to diverse settings (Bradberry \& Greaves, 2010). The EIA comprises of 28 items that facilitate the measurement of the four major components which are - Self-Awareness, Social Awareness, SelfManagement, and Relationship Management. It takes each participant approximately 7-10 minutes to successfully complete the EIA assessment. These items refer to behavioural statements for different situations that link the presence of skills representing Self-Awareness, Social Awareness, Self-Management, and Relationship Management components. These components are rated by employing a six-point Likert frequency scale where 1 indicates "never" and 6 indicates "always" representing the stated behaviour (Bradberry \& Greaves, 2010). It is imperative to clarify that the EIA has three versions which are: Me Edition (online, booklet and consultant self-report), Multi-Rater, and $360^{\circ}$ Edition (self-report and report from others towards the person being measured) (TalentSmart, 2020). This study implemented the 'Me Edition' in booklet format which is a subscription package via the TalentSmart website. The 'Me Edition' was then transcribed into an excel sheet to facilitate sharing with the study participants and to ease the capture of the digital measures. The EIA was deployed for this 
study due to its proven validity, ease of completion by participants and the reduced number of questions compared to other existing measurement instruments (Bradberry \& Greaves, 2010).

\section{Rahim Organizational Conflict Inventory-II (ROCI-II)}

The Rahim Organizational Conflict Inventory-II (ROCI-II) was adopted to measure the preferred conflict management styles of the participants. The ROCI-II is a 28 -item questionnaire designed by Rahim (1983b) to measure five independent conflict management styles: avoidance, competition, compromise, accommodation, and collaboration. The instrument includes three forms that are used for assessing how organisational members manage conflict with superiors, subordinates, and peers respectively. This study made use of the three forms by condensing them into a single Excel sheet and participants were required to rate the different applicable columns. This is determined on the basis of pattern repetition and the sum of the items scores for responses on a 5-point Likert scale to each statement. A higher score represents a greater preference for a specific conflict management style against the others. The implementation of the ROCI-II measure for this study is due to its broad application and the verified validity and reliability indicated in the ROCI-II Professional Manual (ROCI-II PM) (Rahim, 1983b). The internal consistency reliability coefficient is considered satisfactory using Cronbach's alpha, Spearman-Brown Reliability, Guttman Lambda and Kristof's Unbiased Estimate of Reliability. This is in comparison with related instruments like the ThomasKilmann Conflict Mode Instrument (TKI). The ROCI-II test-retest and Cronbach's alpha reliabilities are also found to be favourable (Ben-Yoav \& Banai, 1992).

\section{Data analysis procedures}

The data gathering was transferred to Excel sheet including the individual participants' unique sequential identification number along with their personal characteristics from the demographic questionnaire. This data transfer also included their dimensions and overall scores from the emotional intelligence EIA questionnaire, and the participants' preferred conflict management styles from the ROCI-II questionnaire. Three types of statistical instruments were used to analyse the sample demographics, the emotional intelligence levels, the preferred conflict management styles, and the relationships between these variables.

For RQ1, RQ2 and RQ3 (see Table 1), the descriptive statistics including frequencies, means, standard deviations and variance were employed to draw conclusions regarding the participant's demographics, EI levels, and CM styles (Donnelly \& Abdel-Raouf, 2016). For RQ4 and RQ5, inferential statistics was employed for testing the hypothesis. A one-way ANOVA (analysis of variance) was used to examine the existence or non-significant statistical differences in emotional intelligence levels and conflict management styles based on the sample demographics. The one-way ANOVA was used to compare the means between independent groups and determine whether any of those means are statistically significantly different from each other (Salkind, 2010). The Pearson's correlation was used to explore the correlation between emotional intelligence levels and conflict management styles. The Pearson's correlation coefficient is useful for addressing the need to quantitatively measure the magnitude and direction of the linear association that might exist between two variables on an interval range (Salkind, 2010).

\section{THE RESULTS}

\section{EI Levels}


The emotional intelligence was assessed using the EIA measure, which is based on Goleman's four-dimensional model of EI with scores from 1 to 100 for each dimension. The range of these scores determines the emotional intelligence levels (see Table 3). The descriptive statistics was analysed for each of the dimensions, including the total EI. These statistics included the frequency $(\mathrm{N})$ of the participants' results at such levels and their percentage $(\%)$ in relation to the grand total, the minimum (Min) and maximum (Max) EI scores, the mean (M) score, the standard deviation (SD) and the variance (Var) of the resulting data in relation to the mean.

Table 3 - Emotional Intelligence Levels and Descriptive Statistics

Emotional Intelligence Levels

\section{Descriptive Statistics}

\begin{tabular}{|c|c|c|c|c|c|c|c|}
\hline Self-Awareness & $\mathbf{N}$ & $\%$ & Min & $\operatorname{Max}$ & $\mathbf{M}$ & SD & Var \\
\hline Very High & 7 & 0.14 & 91 & 97 & 93.57 & 2.70 & 7.29 \\
\hline High & 21 & 0.43 & 82 & 88 & 83.86 & 2.01 & 4.03 \\
\hline Moderate & 16 & 0.33 & 72 & 78 & 75.19 & 2.56 & 6.56 \\
\hline Low & 4 & 0.08 & 63 & 66 & 65.25 & 1.50 & 2.25 \\
\hline Very Low & 1 & 0.02 & 57 & 57 & 57.00 & & \\
\hline Grand Total & 49 & 1.00 & 57 & 97 & 80.35 & 8.65 & 74.90 \\
\hline Self-Management & $\mathbf{N}$ & $\%$ & Min & Max & $\mathbf{M}$ & SD & Var \\
\hline High & 20 & 0.41 & 81 & 89 & 84.30 & 2.62 & 6.85 \\
\hline Moderate & 17 & 0.35 & 71 & 79 & 75.35 & 3.18 & 10.12 \\
\hline Low & 12 & 0.24 & 61 & 69 & 65.67 & 2.87 & 8.24 \\
\hline Grand Total & 49 & 1.00 & 61 & 89 & 76.63 & 7.94 & 63.11 \\
\hline Social Awareness & $\mathbf{N}$ & $\%$ & Min & Max & $\mathbf{M}$ & SD & Var \\
\hline Very High & 7 & 0.14 & 90 & 100 & 94.29 & 3.45 & 11.90 \\
\hline High & 19 & 0.39 & 80 & 87 & 82.42 & 2.78 & 7.70 \\
\hline Moderate & 15 & 0.31 & 70 & 77 & 73.47 & 2.83 & 7.98 \\
\hline Low & 6 & 0.12 & 64 & 67 & 64.50 & 1.22 & 1.50 \\
\hline Very Low & 2 & 0.04 & 51 & 58 & 54.50 & 4.95 & 24.50 \\
\hline Grand Total & 49 & 1.00 & 51 & 100 & 78.04 & 10.30 & 106.00 \\
\hline
\end{tabular}

\begin{tabular}{ccccccccc} 
Relationship Management & $\mathbf{N}$ & $\mathbf{\%}$ & Min & Max & M & SD & Var \\
\hline Very High & 2 & 0.04 & 91 & 91 & 91.00 & 0.00 & 0.00 \\
\hline High & 23 & 0.47 & 81 & 89 & 83.87 & 2.82 & 7.94 \\
\hline Moderate & 15 & 0.31 & 71 & 79 & 75.40 & 2.64 & 6.97 \\
Low & 9 & 0.18 & 61 & 69 & 65.22 & 3.07 & 9.44 \\
\hline \hline Grand Total & $\mathbf{4 9}$ & $\mathbf{1 . 0 0}$ & $\mathbf{6 1}$ & $\mathbf{9 1}$ & $\mathbf{7 8 . 1 4}$ & $\mathbf{7 . 9 7}$ & $\mathbf{6 3 . 5 0}$ \\
Total EI & & & & & & & & Var \\
High & $\mathbf{N}$ & $\mathbf{\%}$ & $\mathbf{M i n}$ & $\mathbf{M a x}$ & $\mathbf{M}$ & $\mathbf{S D}$ & 2.32 & 5.40 \\
\hline Moderate & 27 & 0.55 & 80 & 88 & 83.59 & 74.44 & 2.99 & 8.93 \\
Low & 16 & 0.33 & 70 & 79 & 61 & 2.23 & 4.97 \\
\hline \hline Grand Total & 6 & 0.12 & 61 & 67 & 65.17 & $\mathbf{4 8}$ & $\mathbf{4 8 . 5 2}$
\end{tabular}


The EIL resulted in variations between the different dimensions of EI (Table 3). For selfawareness, these scores varied from "very low" $(\mathrm{Min}=57)$ to "very high" $(\mathrm{Max}=97)$ with a total mean of 80.35. The total standard deviation and variance for this dimension were 8.65 and 74.90, respectively. On the other hand, the EIL for self-management varied from "low" $(\mathrm{Min}=61)$ to "high" $(\mathrm{Max}=89)$ with a total mean of 76.63 ; standard deviation of 7.94 and variance of 63.11. For social awareness, the scores varied from "very low" to "very high" i.e. $(\mathrm{Min}=51$ and Max =89), with mean score of 78.04 and higher standard deviation of 10.30 and variance of $106.00(\mathrm{Var}=106.00)$ compared to the other EI dimensions. For relationship management, the scores varied from "low" $(\mathrm{Min}=61)$ to "very high" $(\mathrm{Max}=91)$ with a mean score of $(M=78.14)$, standard deviation $(S D=7.97)$ and variance $(\operatorname{Var}=63.50)$. The overall emotional intelligence scores i.e. total EI, representing low to high levels of EI was 61 and 88, and with a mean score of 78.35, standard deviation of 6.97 and variance of 48.52 . Figure 1 shows the average EI scores for the four dimensions including the total EI, indicating that selfawareness had the highest EQ while self-management had the lowest average score. Table 3 shows that 27 participants (55\%), can be classified as having high level of emotional intelligence whilst $16(33 \%)$ participants attained moderate levels, and 6 participants $(12 \%)$ exhibited signs of low level of emotional intelligence.

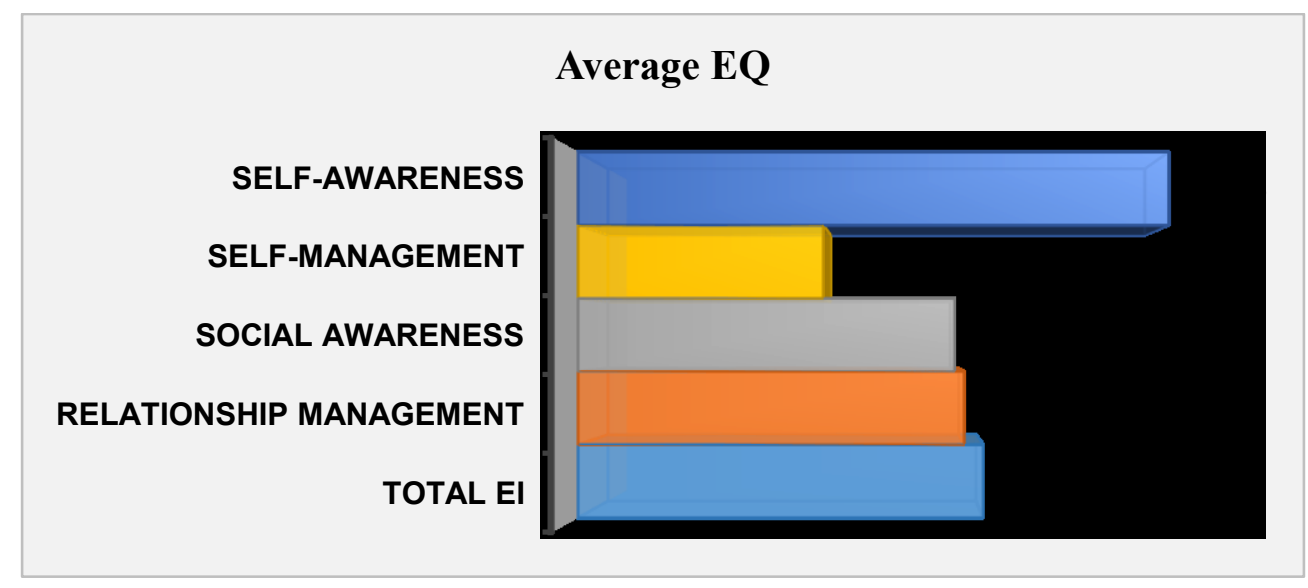

Figure 1 - Average Emotional Intelligence Scores

\section{Conflict Management Styles (CMS)}

The preferred conflict management styles in the Dominican Republic construction industry was evaluated using the ROCI-II measure, in accordance with Rahim's five-style model of CM with scores ranging from 0.00 to 5.00 for each style. The scale of these scores determine the level of preference for conflict management styles when managing conflicts with either superiors, subordinates or peers, including an overall average between the three groups.

The preferred conflict management style when dealing with superiors resulted in some differences between the five CMS (Table 4). For avoidance, compromise, accommodation and collaboration styles, the scores varied from a minimum of 2.00 (moderate) to a maximum of 5.00 (very high) with a mean score ranging from 3.62 to 4.52 . The standard deviation ranged from 0.45 to 0.68 , with a variance from 0.20 to 0.47 . The resulting collaboration style had the highest mean score $(\mathrm{M}=4.52)$ and the lowest standard deviation $(\mathrm{SD}=0.45)$ with a variance of 0.20 . On the other hand, the scores for competition style varied from "low" (Min = 1.00) to "very high" (Max $=4.60)$, resulting in the lowest mean $(\mathrm{M}=2.87)$, and the highest standard deviation $(\mathrm{SD}=0.79)$ with a variance of 0.63 . 
Table 4 - Conflict Management Styles with Superiors

\begin{tabular}{|c|c|c|c|c|c|c|c|}
\hline Avoidance & $\mathbf{N}$ & $\%$ & Min & Max & $\mathbf{M}$ & SD & Var \\
\hline Very High & 20 & 0.41 & 4.00 & 4.67 & 4.28 & 0.27 & 0.07 \\
\hline High & 19 & 0.39 & 3.00 & 3.83 & 3.46 & 0.28 & 0.08 \\
\hline Moderate & 10 & 0.20 & 2.33 & 2.83 & 2.62 & 0.16 & 0.02 \\
\hline Trand Total & 49 & 1.00 & 2.33 & 4.67 & 3.62 & 0.68 & 0.47 \\
\hline Competition & $\mathbf{N}$ & $\%$ & Min & Max & $\mathbf{M}$ & SD & Var \\
\hline Very High & 5 & 0.10 & 4.00 & 4.60 & 4.12 & 0.27 & 0.07 \\
\hline High & 21 & 0.43 & 3.00 & 3.80 & 3.32 & 0.24 & 0.06 \\
\hline Moderate & 16 & 0.33 & 2.00 & 2.80 & 2.45 & 0.25 & 0.06 \\
\hline Low & 7 & 0.14 & 1.00 & 1.80 & 1.54 & 0.28 & 0.08 \\
\hline Grand Total & 49 & 1.00 & 1.00 & 4.60 & 2.87 & 0.79 & 0.63 \\
\hline Compromise & $\mathbf{N}$ & $\%$ & Min & Max & M & SD & Var \\
\hline Very High & 33 & 0.67 & 4.00 & 5.00 & 4.37 & 0.31 & 0.10 \\
\hline High & 15 & 0.31 & 3.00 & 3.75 & 3.47 & 0.31 & 0.10 \\
\hline Moderate & 1 & 0.02 & 2.00 & 2.00 & 2.00 & & \\
\hline Grand Total & 49 & 1.00 & 2.00 & 5.00 & 4.05 & 0.60 & 0.36 \\
\hline Accommodation & $\mathbf{N}$ & $\%$ & Min & Max & $\mathbf{M}$ & SD & Var \\
\hline Very High & 20 & 0.41 & 4.00 & 4.83 & 4.37 & 0.28 & 0.08 \\
\hline High & 27 & 0.55 & 3.00 & 3.83 & 3.54 & 0.26 & 0.07 \\
\hline Moderate & 2 & 0.04 & 2.33 & 2.67 & 2.50 & 0.24 & 0.06 \\
\hline Grand Total & 49 & 1.00 & 2.33 & 4.83 & 3.84 & 0.55 & 0.31 \\
\hline Collaboration & $\mathbf{N}$ & $\%$ & Min & Max & $\mathbf{M}$ & SD & Var \\
\hline Very High & 44 & 0.90 & 4.00 & 5.00 & 4.63 & 0.29 & 0.08 \\
\hline High & 4 & 0.08 & 3.43 & 3.86 & 3.75 & 0.21 & 0.05 \\
\hline Moderate & 1 & 0.02 & 2.71 & 2.71 & 2.71 & & \\
\hline Grand Total & 49 & 1.00 & 2.71 & 5.00 & 4.52 & 0.45 & 0.20 \\
\hline
\end{tabular}

The total mean score for each of the five conflict management styles show that collaboration and compromise styles were the most preferred, followed by accommodation and avoidance. The least preferred style by the respondents was competition which has the lowest average score (Figure 2). 


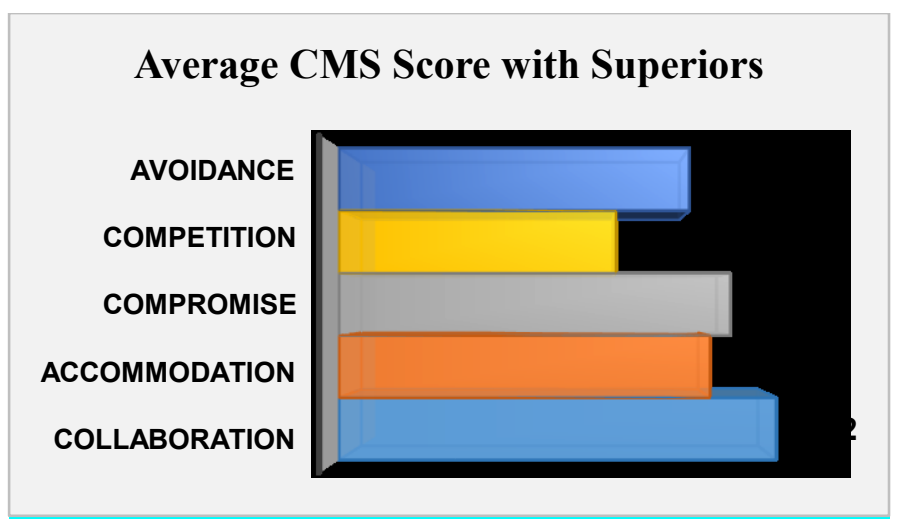

Figure 2 - Average CMS Scores with Superiors

The preferred conflict management styles when dealing with subordinates also resulted in some differences between the five CMS (Table 5). The mean score for compromise, accommodation and collaboration styles for managing conflicts with subordinates ranged from 3.24 to 4.35; standard deviation from 0.44 to 0.75 ; with a variance of 0.19 to 0.56 . For avoidance and competition styles, they both had similar mean scores $(\mathrm{M}=3.14$ and $\mathrm{M}=3.15)$, but the competition style had the highest standard deviation $(\mathrm{SD}=0.94)$ with a variance of 0.88 . The collaboration style had the highest mean score and lowest standard deviation and variance. The findings suggest that managing conflict with subordinates indicates collaboration and compromise styles to be "very high" preferences for participants. Although accommodation, competition, and avoidance styles had the lowest average scores, they were still considered as "high" preferences for a number of participants (Figure 3).

Table 5 - Conflict Management Styles with Subordinates

\begin{tabular}{cccccccc} 
Avoidance & $\mathbf{N}$ & $\mathbf{\%}$ & $\mathbf{M i n}$ & $\mathbf{M a x}$ & $\mathbf{M}$ & $\mathbf{S D}$ & $\mathbf{V a r}$ \\
\hline Very High & 9 & 0.18 & 4.00 & 4.67 & 4.20 & 0.23 & 0.05 \\
\hline High & 23 & 0.47 & 3.00 & 3.83 & 3.41 & 0.28 & 0.08 \\
Moderate & 13 & 0.27 & 2.00 & 2.83 & 2.45 & 0.23 & 0.05 \\
\hline Low & 4 & 0.08 & 1.17 & 1.67 & 1.42 & 0.22 & 0.05 \\
\hline Grand Total & $\mathbf{4 9}$ & $\mathbf{1 . 0 0}$ & $\mathbf{1 . 1 7}$ & $\mathbf{4 . 6 7}$ & $\mathbf{3 . 1 4}$ & $\mathbf{0 . 8 3}$ & $\mathbf{0 . 6 9}$ \\
& & & & & & & \\
Competition & $\mathbf{N}$ & $\mathbf{\%}$ & $\mathbf{M i n}$ & $\mathbf{M a x}$ & $\mathbf{M}$ & $\mathbf{S D}$ & $\mathbf{V a r}$ \\
\hline Very High & 10 & 0.20 & 4.00 & 5.00 & 4.34 & 0.39 & 0.15 \\
\hline High & 21 & 0.43 & 3.00 & 3.80 & 3.45 & 0.33 & 0.11 \\
\hline Moderate & 11 & 0.22 & 2.20 & 2.80 & 2.49 & 0.27 & 0.07 \\
\hline Low & 7 & 0.14 & 1.00 & 1.80 & 1.60 & 0.31 & 0.09 \\
\hline Grand Total & $\mathbf{4 9}$ & $\mathbf{1 . 0 0}$ & $\mathbf{1 . 0 0}$ & $\mathbf{5 . 0 0}$ & $\mathbf{3 . 1 5}$ & $\mathbf{0 . 9 4}$ & $\mathbf{0 . 8 8}$ \\
& & & & & & & \\
\hline Compromise & $\mathbf{N}$ & $\mathbf{\%}$ & $\mathbf{M i n}$ & $\mathbf{M a x}$ & $\mathbf{M}$ & $\mathbf{S D}$ & $\mathbf{V a r}$ \\
\hline Very High & 29 & 0.67 & 4.00 & 5.00 & 4.42 & 0.34 & 0.12 \\
\hline High & 15 & 0.27 & 3.00 & 3.75 & 3.47 & 0.28 & 0.08 \\
\hline Moderate & 5 & 0.06 & 2.00 & 2.75 & 2.40 & 0.29 & 0.08
\end{tabular}




\begin{tabular}{|c|c|c|c|c|c|c|c|}
\hline Grand Total & 49 & 1.00 & 2.00 & 5.00 & 3.92 & 0.75 & 0.56 \\
\hline Accommodation & $\mathbf{N}$ & $\%$ & Min & $\operatorname{Max}$ & $\mathbf{M}$ & SD & Var \\
\hline Very High & 2 & 0.04 & 4.00 & 4.33 & 4.17 & 0.24 & 0.06 \\
\hline High & 33 & 0.67 & 3.00 & 3.83 & 3.42 & 0.29 & 0.09 \\
\hline Moderate & 14 & 0.29 & 2.17 & 2.83 & 2.67 & 0.24 & 0.06 \\
\hline Grand Total & 49 & 1.00 & 2.17 & 4.33 & 3.24 & 0.48 & 0.23 \\
\hline Collaboration & $\mathbf{N}$ & $\%$ & Min & Max & $\mathbf{M}$ & SD & Var \\
\hline Very High & 41 & 0.84 & 4.00 & 5.00 & 4.49 & 0.33 & 0.11 \\
\hline High & 8 & 0.16 & 3.29 & 3.86 & 3.64 & 0.20 & 0.04 \\
\hline Trand Total & 49 & 1.00 & 3.29 & 5.00 & 4.35 & 0.44 & 0.19 \\
\hline
\end{tabular}

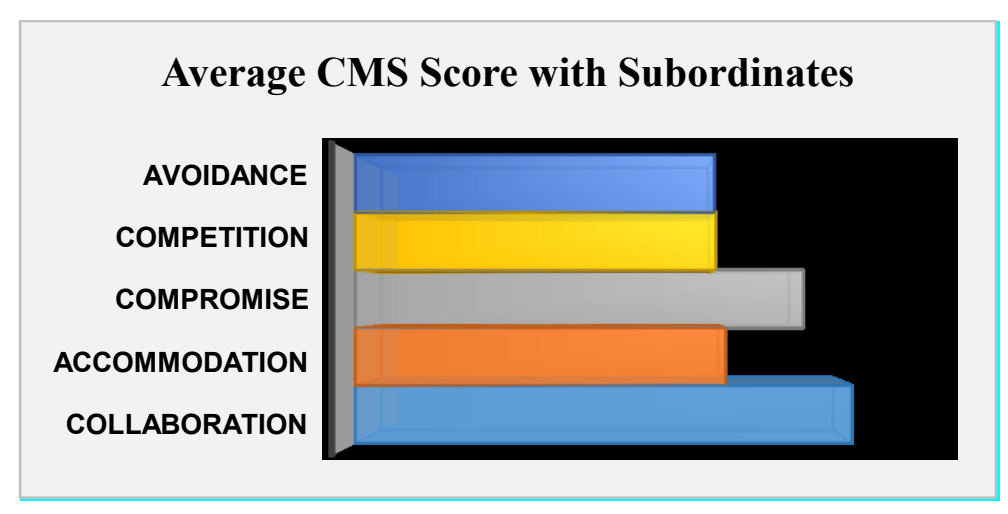

Figure 3 - Average CMS Scores with Subordinates

The preferred conflict management styles (compromise, accommodation, and collaboration) when dealing with peers reflects a mean score ranging from 3.37 to 4.54 (Figure 4), with standard deviation of 0.40 to 0.60 , and variance from 0.16 to 0.36 (Table 6 ). The collaboration style had the highest mean score, lowest standard deviation, and variance, thus making it the most favoured by the participants. The competition style had the lowest mean $(M=3.01)$ score similar to the previous groups on how conflicts are handled, and likewise with the highest standard deviation $(\mathrm{SD}=0.83$ ) and variance of 0.69 . This is very similar to the values of conflict management styles with superiors. Figure 4 shows that when managing conflicts with peers, collaboration and compromise styles seem to be the preferred choice with "very high" preferences as indicated in this study.

Table 6 - Conflict Management Styles with Peers

\begin{tabular}{cccccccc} 
Avoidance & $\mathbf{N}$ & $\mathbf{\%}$ & Min & Max & M & SD & Var \\
\hline Very High & 12 & 0.24 & 4.00 & 4.67 & 4.31 & 0.24 & 0.06 \\
\hline High & 24 & 0.49 & 3.00 & 3.83 & 3.36 & 0.29 & 0.09 \\
Moderate & 10 & 0.20 & 2.17 & 2.83 & 2.55 & 0.21 & 0.04 \\
\hline Low & 3 & 0.06 & 1.50 & 1.83 & 1.72 & 0.19 & 0.04 \\
\hline \hline Grand Total & $\mathbf{4 9}$ & $\mathbf{1 . 0 0}$ & $\mathbf{1 . 5 0}$ & $\mathbf{4 . 6 7}$ & $\mathbf{3 . 3 3}$ & $\mathbf{0 . 7 7}$ & $\mathbf{0 . 5 9}$
\end{tabular}




\begin{tabular}{|c|c|c|c|c|c|c|c|}
\hline Competition & $\mathbf{N}$ & $\%$ & Min & Max & $\mathbf{M}$ & SD & Var \\
\hline Very High & 3 & 0.06 & 4.00 & 4.80 & 4.53 & 0.46 & 0.21 \\
\hline High & 27 & 0.55 & 3.00 & 3.80 & 3.43 & 0.29 & 0.08 \\
\hline Moderate & 12 & 0.24 & 2.00 & 2.80 & 2.53 & 0.29 & 0.08 \\
\hline Low & 7 & 0.14 & 1.00 & 1.80 & 1.57 & 0.29 & 0.09 \\
\hline Grand Total & 49 & 1.00 & 1.00 & 4.80 & 3.01 & 0.83 & 0.69 \\
\hline Compromise & $\mathbf{N}$ & $\%$ & Min & Max & M & SD & Var \\
\hline Very High & 31 & 0.63 & 4.00 & 5.00 & 4.35 & 0.35 & 0.12 \\
\hline High & 17 & 0.35 & 3.00 & 3.75 & 3.40 & 0.28 & 0.08 \\
\hline Moderate & 1 & 0.02 & 2.50 & 2.50 & 2.50 & & \\
\hline Grand Total & 49 & 1.00 & 2.50 & 5.00 & 3.98 & 0.60 & 0.36 \\
\hline Accommodation & $\mathbf{N}$ & $\%$ & Min & Max & M & SD & Var \\
\hline Very High & 5 & 0.10 & 4.00 & 4.17 & 4.07 & 0.09 & 0.01 \\
\hline High & 34 & 0.69 & 3.00 & 3.83 & 3.47 & 0.28 & 0.08 \\
\hline Moderate & 10 & 0.20 & 2.33 & 2.83 & 2.67 & 0.16 & 0.02 \\
\hline Grand Total & 49 & 1.00 & 2.33 & 4.17 & 3.37 & 0.47 & 0.22 \\
\hline Collaboration & $\mathbf{N}$ & $\%$ & Min & Max & M & SD & Var \\
\hline Very High & 46 & 0.94 & 4.00 & 5.00 & 4.60 & 0.34 & 0.11 \\
\hline High & 3 & 0.06 & 3.29 & 3.86 & 3.67 & 0.33 & 0.11 \\
\hline Grand Total & 49 & 1.00 & 3.29 & 5.00 & 4.54 & 0.40 & 0.16 \\
\hline
\end{tabular}

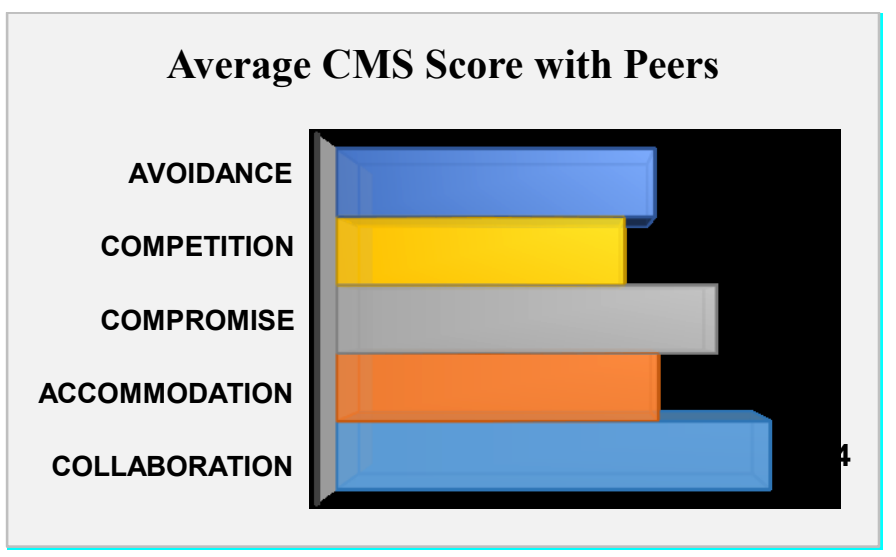

Figure 4 - Average CMS Scores with Peers

\section{Conflict Management Styles Overall}

The overall conflict management styles refer to the average value of the resulting scores when resolving conflicts with superiors, subordinates, and peer groups. For compromise, accommodation and collaboration styles, the mean score ranged from 3.48 to 4.45 (Figure 5). The standard deviation ranged from 0.42 to 0.59 , and with a variance of 0.18 to 0.35 (Table 7). This depicts that collaboration and compromise styles have the highest mean score $(M=4.45$ and $\mathrm{M}=3.98$, respectively), and they are both considered as the most preferred conflict management styles. However, the accommodation style resulted in the lowest standard 
deviation $(\mathrm{SD}=0.42)$ and variance of 0.18 , while scores for avoidance and competition styles varied, with the competition style having the lowest mean score $(\mathrm{M}=3.01)$, and the highest standard deviation $(\mathrm{SD}=0.81)$ with a variance of 0.66 .

Table 7 - Overall Conflict Management Styles

Conflict Management Style - Overall Preference

Descriptive Statistics

\begin{tabular}{|c|c|c|c|c|c|c|c|}
\hline Avoidance & $\mathbf{N}$ & $\%$ & Min & Max & $\mathbf{M}$ & SD & Var \\
\hline Very High & 12 & 0.24 & 4.00 & 4.67 & 4.22 & 0.21 & 0.04 \\
\hline High & 23 & 0.47 & 3.00 & 3.89 & 3.46 & 0.27 & 0.07 \\
\hline Moderate & 12 & 0.24 & 2.17 & 2.94 & 2.58 & 0.23 & 0.05 \\
\hline Low & 2 & 0.04 & 1.83 & 1.89 & 1.86 & 0.04 & 0.00 \\
\hline Grand Total & 49 & 1.00 & 1.83 & 4.67 & 3.36 & 0.70 & 0.49 \\
\hline Competition & $\mathbf{N}$ & $\%$ & Min & Max & $\mathbf{M}$ & SD & Var \\
\hline Very High & 3 & 0.06 & 4.00 & 4.80 & 4.47 & 0.42 & 0.17 \\
\hline High & 24 & 0.49 & 3.00 & 3.93 & 3.48 & 0.24 & 0.06 \\
\hline Moderate & 14 & 0.29 & 2.20 & 2.93 & 2.68 & 0.25 & 0.06 \\
\hline Low & 8 & 0.16 & 1.00 & 1.93 & 1.63 & 0.31 & 0.09 \\
\hline Grand Total & 49 & 1.00 & 1.00 & 4.80 & 3.01 & 0.81 & 0.66 \\
\hline Compromise & $\mathbf{N}$ & $\%$ & Min & Max & M & SD & Var \\
\hline Very High & 29 & 0.59 & 4.00 & 5.00 & 4.36 & 0.32 & 0.10 \\
\hline High & 17 & 0.35 & 3.00 & 3.92 & 3.57 & 0.30 & 0.09 \\
\hline Moderate & 3 & 0.06 & 2.33 & 2.92 & 2.64 & 0.30 & 0.09 \\
\hline Grand Total & 49 & 1.00 & 2.33 & 5.00 & 3.98 & 0.59 & 0.35 \\
\hline Accommodation & $\mathbf{N}$ & $\%$ & Min & Max & M & SD & Var \\
\hline Very High & 4 & 0.08 & 4.00 & 4.33 & 4.14 & 0.14 & 0.02 \\
\hline High & 38 & 0.78 & 3.00 & 3.94 & 3.55 & 0.26 & 0.07 \\
\hline Moderate & 7 & 0.14 & 2.28 & 2.94 & 2.75 & 0.23 & 0.05 \\
\hline Grand Total & 49 & 1.00 & 2.28 & 4.33 & 3.48 & 0.42 & 0.18 \\
\hline Collaboration & $\mathbf{N}$ & $\%$ & Min & Max & M & SD & Var \\
\hline Very High & 43 & 0.88 & 4.00 & 5.00 & 4.58 & 0.26 & 0.07 \\
\hline High & 5 & 0.10 & 3.38 & 3.86 & 3.70 & 0.21 & 0.05 \\
\hline Moderate & 1 & 0.02 & 2.81 & 2.81 & 2.81 & & \\
\hline Grand Total & 49 & 1.00 & 2.81 & 5.00 & 4.45 & 0.44 & 0.19 \\
\hline
\end{tabular}

The total mean score for the five conflict management styles indicate that collaboration and compromise styles ("very high") were the most preferable by the participants; accommodation and avoidance were also "high" in terms of preference but the competition style was the least preferable, see Figure 5. 


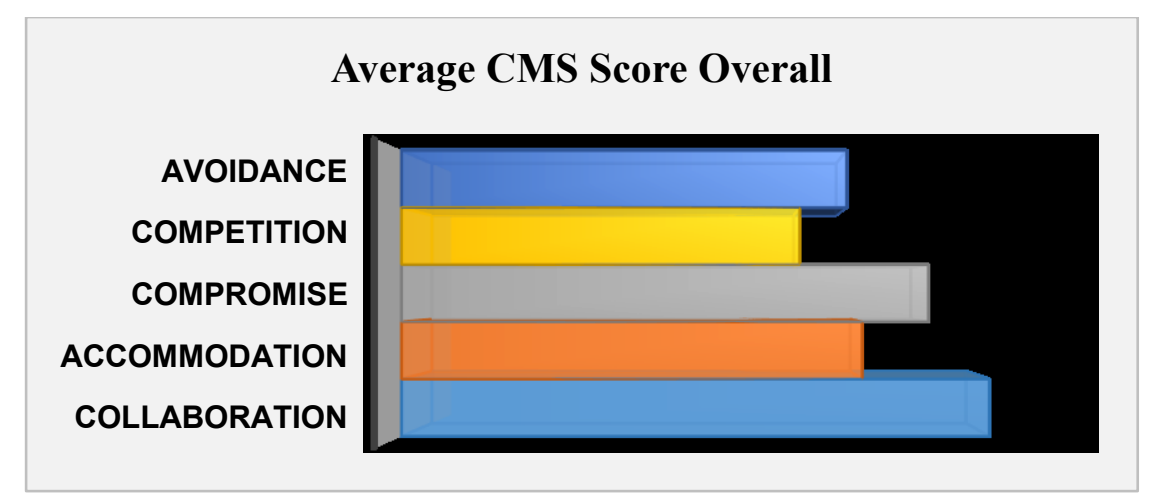

Figure 5 - Preferred Conflict Management Styles Overall

\section{Demography vs Emotional Quotient (EQ)}

The demographic variables considered in this study are gender, age, and years of work experience. The relationship between these demographic variables and emotional intelligence scores are shown graphically by linking each of the demographic variables with the EI dimensions and the total EI. The level of variance between and within the groups were analysed using the one-way ANOVA procedure for inferential statistics by looking at the sum of the squared deviations (SS), the number of degrees of freedom (df), the mean square (MS), and the ratios F, P-value and Fcrit to determine whether the test is statistically significant.

\section{Gender vs EQ}

Figure 6 shows marginal variations between the gender of the participants and the EI scores for the different dimensions including the total EI. The only exception is the social awareness for which the females scored higher with a margin of 4.76. However, the one-way ANOVA analysis (Table 8) determined that this variation was not high enough to be considered as statistically significant. Table 8 show that the values of $\mathrm{F}$ in all EI dimensions are less than Fcrit and that the probability value ( $p$-value) is greater than $0.05(\mathrm{p}>0.05)$. This suggest that gender is not statistically significant regardless of whether the participant is male or female, and the EI scores are not significantly different. 


\section{Gender vs EQ}

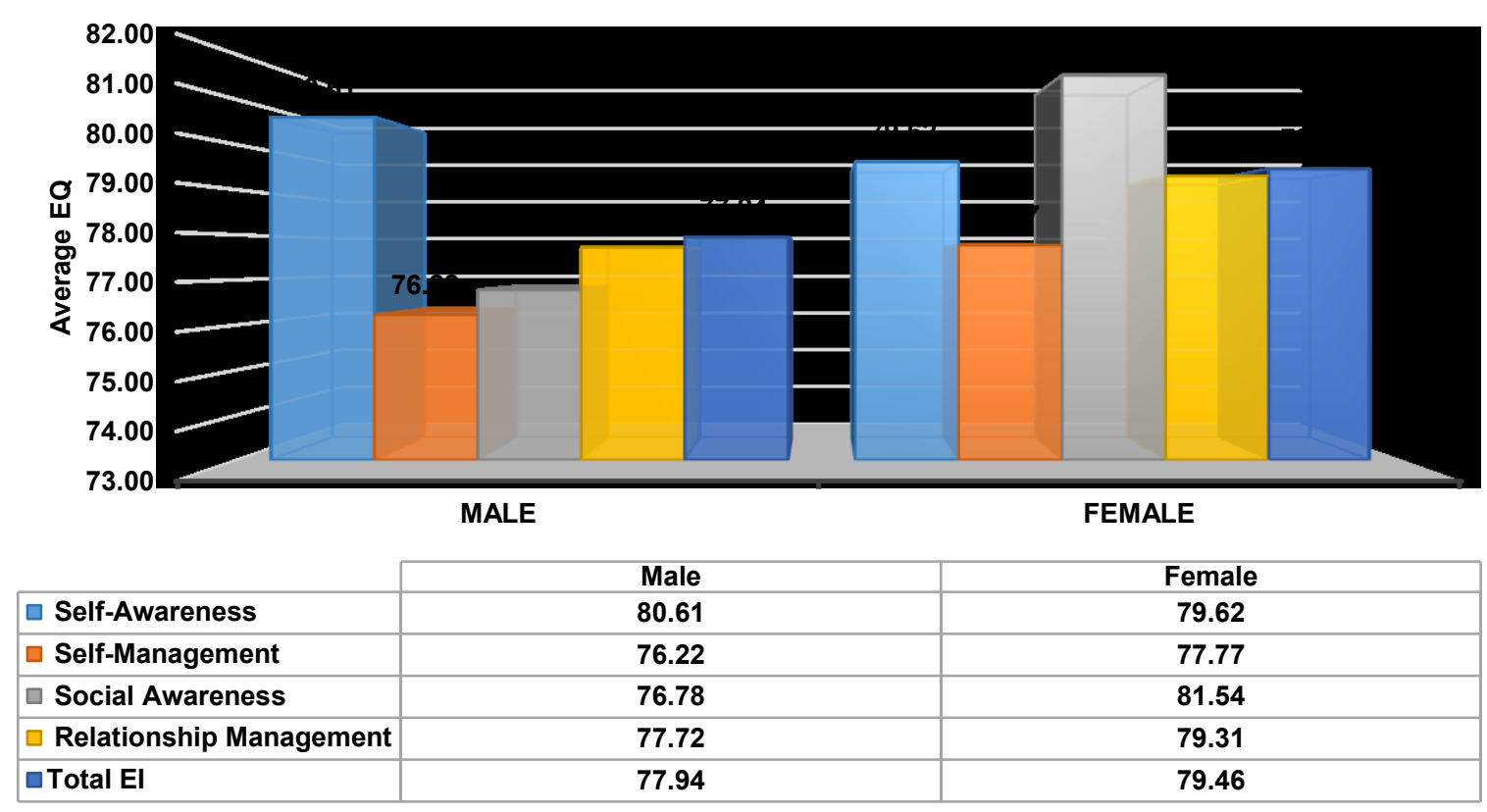

Figure 6 - Gender vs EQ

Table 8-Gender vs EQ and Inferential Statistics
Variables
Inferential Statistics

\begin{tabular}{ccccccc} 
Gender vs Self-Awareness & SS & df & MS & F & P-value & F crit \\
\hline Between Groups & 9.47 & 1 & 9.47 & 0.12 & 0.726 & 4.05 \\
\hline Within Groups & 3585.63 & 47 & 76.29 & & & \\
\hline Total & $\mathbf{3 5 9 5 . 1 0}$ & $\mathbf{4 8}$ & & &
\end{tabular}

\begin{tabular}{ccccccc} 
Gender vs Self-Management & SS & df & MS & F & P-value & F crit \\
\hline Between Groups & 22.86 & 1 & 22.86 & 0.36 & 0.553 & 4.05 \\
\hline Within Groups & 3006.53 & 47 & 63.97 & & & \\
\hline Total & $\mathbf{3 0 2 9 . 3 9}$ & $\mathbf{4 8}$ & & & &
\end{tabular}

\begin{tabular}{ccccccc} 
Gender vs Social Awareness & SS & df & MS & F & P-value & F crit \\
\hline Between Groups & 216.47 & 1 & 216.47 & 2.09 & 0.155 & 4.05 \\
Within Groups & 4871.45 & 47 & 103.65 & & & \\
\hline \hline Total & $\mathbf{5 0 8 7 . 9 2}$ & $\mathbf{4 8}$ & & &
\end{tabular}

\begin{tabular}{cccccccc} 
Gender vs Relationship Management & SS & df & MS & F & P-value & F crit \\
\hline Between Groups & 24.01 & 1 & 24.01 & 0.37 & 0.544 & 4.05 \\
\hline Within Groups & 3023.99 & 47 & 64.34 & & & \\
\hline \hline Total & $\mathbf{3 0 4 8 . 0 0}$ & $\mathbf{4 8}$ & & & &
\end{tabular}




\begin{tabular}{ccccccc} 
Gender vs Total EI & SS & df & MS & F & P-value & F crit \\
\hline Between Groups & 21.98 & 1 & 21.98 & 0.45 & 0.507 & 4.05 \\
\hline Within Groups & 2307.12 & 47 & 49.09 & & \\
\hline Total & $\mathbf{2 3 2 9 . 1 0}$ & $\mathbf{4 8}$ & & & \\
& & & & P-value $<0.05$ Statistically Significant
\end{tabular}

\section{Age vs EQ}

Figure 7 indicates marginal variations between the age of the participants and the total EI score. The data for self-awareness, self-management and relationship management identify that the youngest participants (24 - 30 year olds) scored lower than the older groups with the exception of social awareness where the 24 - 30 year olds had better overall performance. However, the one-way ANOVA analysis (Table 9) suggest that these variations are not high enough to be considered as statistically significant. Table 9 shows that the $\mathrm{F}$ values in all EI dimensions are less than Fcrit and the P-values are greater than 0.05. This implies that the age of the participants was not statistically significant in relation to EI scores.

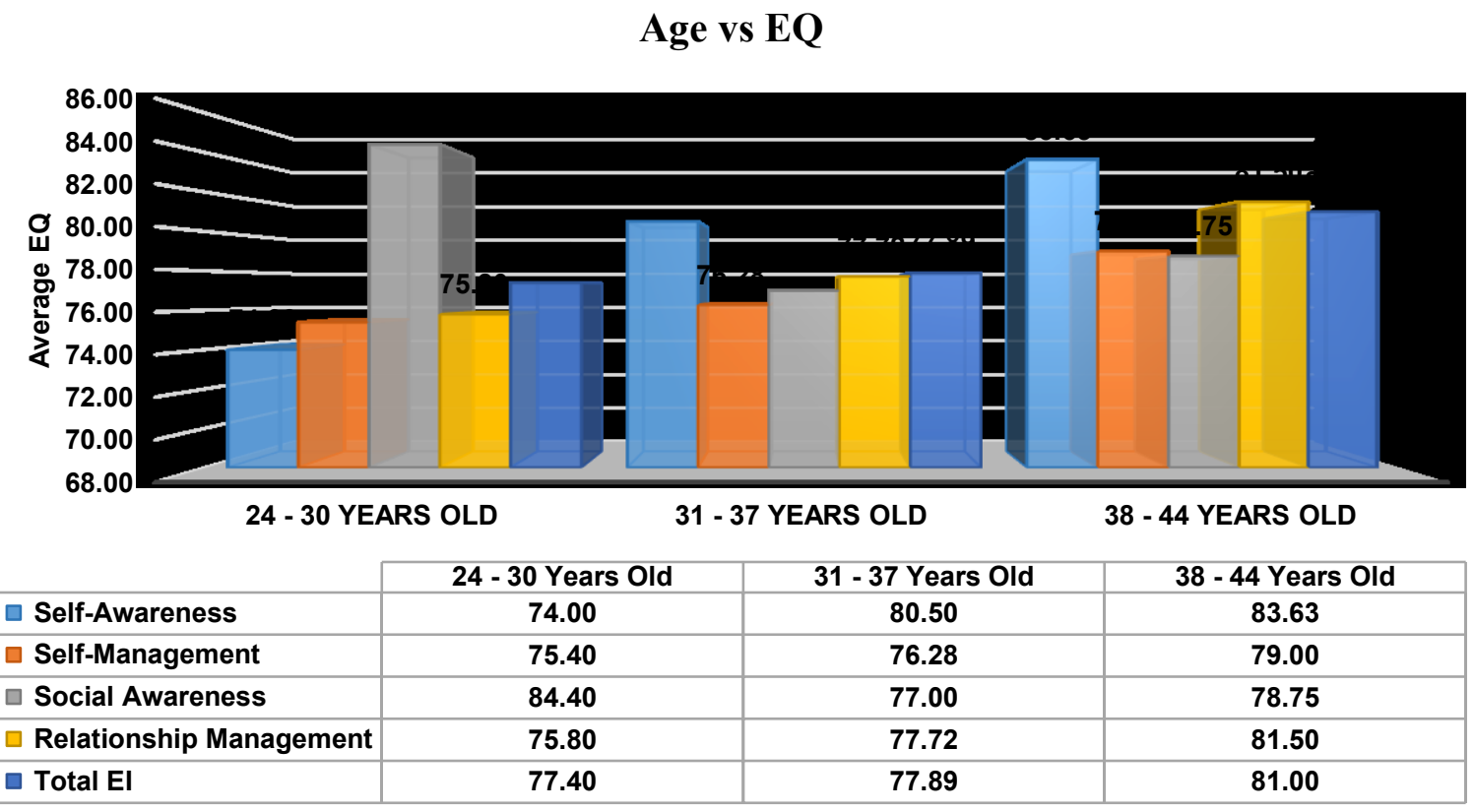

Figure 7 - Age vs EQ

Table 9 - Age vs EQ and Inferential Statistics

Variables

Age vs Self-Awareness

Between Groups

Within Groups
Inferential Statistics

$\begin{array}{cccccc}\text { SS } & \text { df } & \text { MS } & \text { F } & \text { P-value } & \text { F crit } \\ 288.23 & 2 & 144.11 & 2.00 & 0.146 & 3.20 \\ 3306.88 & 46 & 71.89 & & & \end{array}$




\begin{tabular}{ccccccc} 
Age vs Self-Management & SS & df & MS & F & P-value & F crit \\
\hline Between Groups & 56.97 & 2 & 28.48 & 0.44 & 0.646 & 3.20 \\
\hline Within Groups & 2972.42 & 46 & 64.62 & & & \\
\hline Total & $\mathbf{3 0 2 9 . 3 9}$ & $\mathbf{4 8}$ & & &
\end{tabular}

\begin{tabular}{ccccccc} 
Age vs Social Awareness & SS & df & MS & F & P-value & F crit \\
\hline Between Groups & 245.22 & 2 & 122.61 & 1.16 & 0.321 & 3.20 \\
\hline Within Groups & 4842.70 & 46 & 105.28 & & & \\
\hline \hline Total & $\mathbf{5 0 8 7 . 9 2}$ & $\mathbf{4 8}$ & & &
\end{tabular}

\begin{tabular}{ccccccc} 
Age vs Relationship Management & SS & df & MS & F & P-value & F crit \\
\hline Between Groups & 123.98 & 2 & 61.99 & 0.98 & 0.385 & 3.20 \\
\hline Within Groups & 2924.02 & 46 & 63.57 & & & \\
\hline \hline Total & $\mathbf{3 0 4 8 . 0 0}$ & $\mathbf{4 8}$ & & &
\end{tabular}

\begin{tabular}{ccccccc} 
Age vs Total EI & SS & df & MS & F & P-value & F crit \\
\hline Between Groups & 68.35 & 2 & 34.17 & 0.70 & 0.504 & 3.20 \\
\hline Within Groups & 2260.76 & 46 & 49.15 & & & \\
\hline Total & $\mathbf{2 3 2 9 . 1 0}$ & $\mathbf{4 8}$ & & & \\
& & & & P-value $<0.05$ & Statistically Significant
\end{tabular}

\section{Work Experience vs EQ}

The participants with over 6 years of management experience had better overall performance compared to participants with 1-5 years of experience. Figure 8 show minimal variations between the years of work experience (6-11 and 12-17) of the participants and the EQ for all the components including their total EI score. Participants with 1-5 years of experience scored lower than the more experienced groups for self-awareness, self-management and relationship management. The one-way ANOVA analysis (Table 10) confirms that these variations from all the participants were not high enough to be considered statistically significant. Table 10 shows that $\mathrm{F}<\mathrm{F}$ crit for all EI dimensions and P-value $>0.05$ suggest that the years of work experience of the participants were not statistically significant in relation to EQ. 


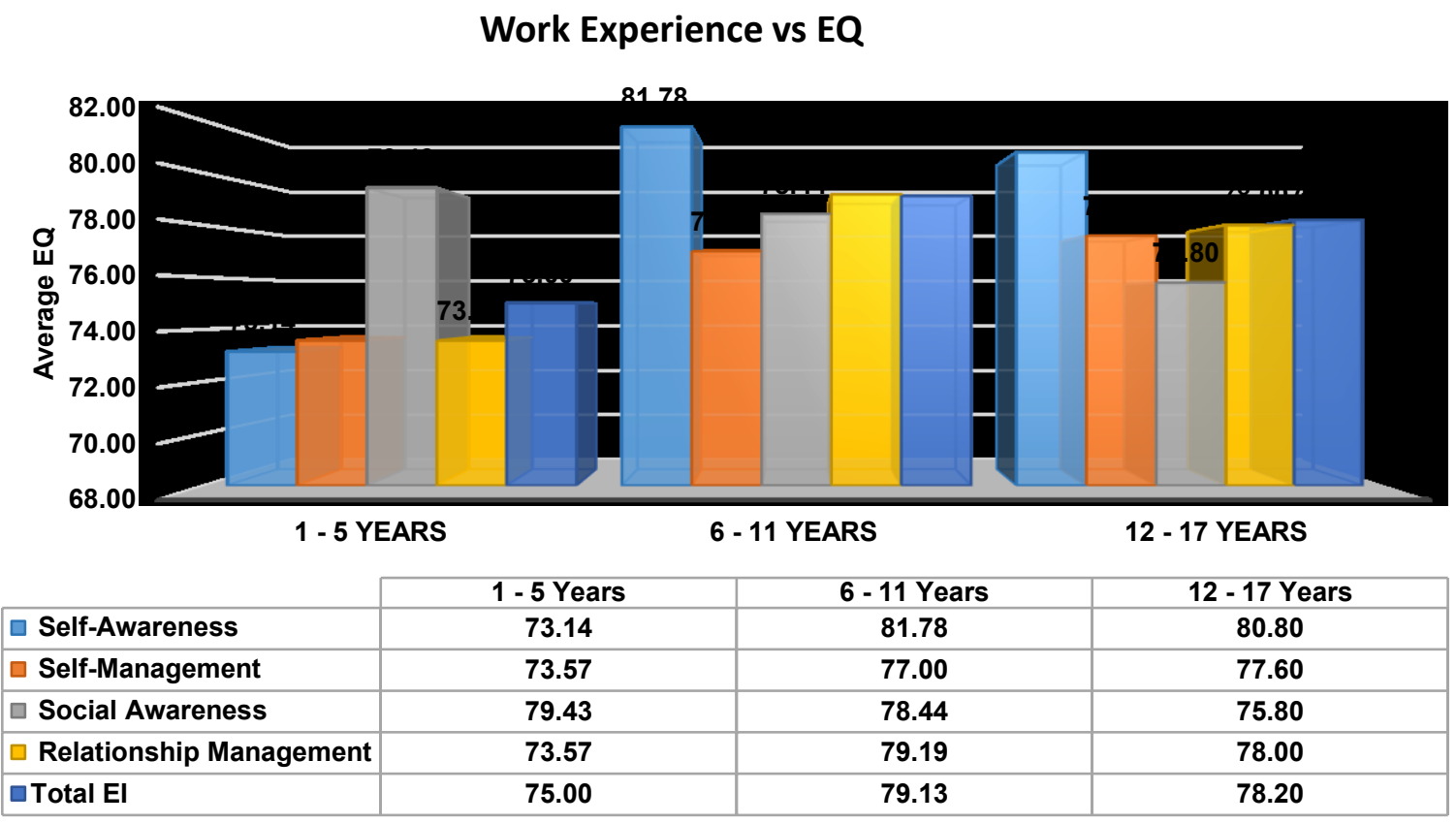

Figure 8 - Work Experience vs EQ

Table 10 - Work Experience vs EQ Inferential Statistics

Variables
Inferential Statistics

\begin{tabular}{cccccccc} 
Work Experience vs Self-Awareness & SS & df & MS & F & P-value & F crit \\
\hline Between Groups & 431.18 & 2 & 215.59 & 3.13 & 0.053 & 3.20 \\
\hline Within Groups & 3163.93 & 46 & 68.78 & & & & \\
\hline \hline Total & $\mathbf{3 5 9 5 . 1 0}$ & $\mathbf{4 8}$ & & & &
\end{tabular}

\begin{tabular}{ccccccc} 
Work Experience vs Self-Management & SS & df & MS & F & P-value & F crit \\
\hline Between Groups & 79.27 & 2 & 39.64 & 0.62 & 0.543 & 3.20 \\
Within Groups & 2950.11 & 46 & 64.13 & & & \\
\hline Total & $\mathbf{3 0 2 9 . 3 9}$ & $\mathbf{4 8}$ & & & &
\end{tabular}

\begin{tabular}{cccccccc} 
Work Experience vs Social Awareness & SS & df & MS & F & P-value & F crit \\
\hline Between Groups & 68.73 & 2 & 34.36 & 0.31 & 0.731 & 3.20 \\
\hline Within Groups & 5019.19 & 46 & 109.11 & & & \\
\hline Total & $\mathbf{5 0 8 7 . 9 2}$ & $\mathbf{4 8}$ & & &
\end{tabular}

\begin{tabular}{ccccccc}
$\begin{array}{c}\text { Work Experience vs Relationship } \\
\text { Management }\end{array}$ & SS & df & MS & F & P-value & F crit \\
\hline Between Groups & 181.41 & 2 & 90.71 & 1.46 & 0.244 & 3.20 \\
\hline Within Groups & 2866.59 & 46 & 62.32 & & & \\
\hline Total & $\mathbf{3 0 4 8 . 0 0}$ & $\mathbf{4 8}$ & & &
\end{tabular}




\begin{tabular}{ccccccc} 
Work Experience vs Total EI & SS & df & MS & F & P-value & F crit \\
\hline Between Groups & 98.00 & 2 & 49.00 & 1.01 & 0.372 & 3.20 \\
\hline Within Groups & 2231.10 & 46 & 48.50 & & & \\
\hline \hline Total & $\mathbf{2 3 2 9 . 1 0}$ & $\mathbf{4 8}$ & & & \\
& & & & P-value $<0.05$ Statistically Significant
\end{tabular}

\section{Demography vs Conflict Management Styles (CMS)}

The impact of gender, age and work experience on overall CMS were analysed and each of the demographic variable was linked to the overall score for individual conflict management styles when dealing with superiors, subordinates, and peers. The level of variance between and within the groups were also analysed by using the one-way ANOVA procedure to determine whether the differences are statistically significant.

\section{Gender vs overall CMS}

The findings as shown in Figure 9 indicate minor variations between the gender of the participants and the average score for all the variables. Both male and female participants preferred compromise and collaboration styles more, and the females performed better than the males in both variables. The statistical significance was analysed using one-way ANOVA. The relationship between gender and avoidance (P-value 0.145), competition (P-value 0.147) and accommodation (P-value 0.343) styles were not statistically significant $(\mathrm{F}<\mathrm{F}$ crit and $\mathrm{P}$ value $>0.05$ ) as shown in Table 11 . However, the compromise (P-value 0.008 ) and collaboration (P-value 0.004) styles were statistically significant between groups ( $\mathrm{F}>\mathrm{Fcrit}$ and $\mathrm{P}$ value $<0.05$ ), with the female participants showing a higher preference for these styles.

\section{Gender vs overall CMS}

\begin{tabular}{|l|l|l|}
\hline & \\
\hline
\end{tabular}

Figure 9 - Gender vs overall CMS 
Table 11 - Gender vs overall CMS Inferential Statistics

Variables

Inferential Statistics

\begin{tabular}{cccccccc} 
Gender vs Avoidance & SS & df & MS & F & P-value & F crit \\
\hline Between Groups & 1.05 & 1 & 1.05 & 2.19 & 0.145 & 4.05 \\
\hline Within Groups & 22.52 & 47 & 0.48 & & & \\
\hline \hline Total & $\mathbf{2 3 . 5 6}$ & $\mathbf{4 8}$ & & &
\end{tabular}

\begin{tabular}{cccccccc} 
Gender vs Competition & SS & df & MS & F & P-value & F crit \\
\hline Between Groups & 1.40 & 1 & 1.40 & 2.18 & 0.147 & 4.05 \\
\hline Within Groups & 30.19 & 47 & 0.64 & & & \\
\hline \hline Total & $\mathbf{3 1 . 5 9}$ & $\mathbf{4 8}$ & & & &
\end{tabular}

\begin{tabular}{ccccccc} 
Gender vs Compromise & SS & df & MS & F & P-value & F crit \\
\hline Between Groups & 2.34 & 1 & 2.34 & 7.58 & 0.008 & 4.05 \\
\hline Within Groups & 14.48 & 47 & 0.31 & & & \\
\hline \hline Total & $\mathbf{1 6 . 8 1}$ & $\mathbf{4 8}$ & & &
\end{tabular}

\begin{tabular}{ccccccc} 
Gender vs Accommodation & SS & df & MS & F & P-value & F crit \\
Between Groups & 0.16 & 1 & 0.16 & 0.92 & 0.343 & 4.05 \\
\hline Within Groups & 8.35 & 47 & 0.18 & & & \\
\hline Total & $\mathbf{8 . 5 2}$ & $\mathbf{4 8}$ & & &
\end{tabular}

\begin{tabular}{ccccccc} 
Gender vs Collaboration & SS & df & MS & F & P-value & F crit \\
\hline Between Groups & 1.49 & 1 & 1.49 & 9.10 & 0.004 & 4.05 \\
\hline Within Groups & 7.68 & 47 & 0.16 & & & \\
\hline Total & $\mathbf{9 . 1 7}$ & $\mathbf{4 8}$ & \multicolumn{3}{c}{ P-value $<0.05$ Statistically Significant }
\end{tabular}

\section{Age vs overall CMS}

The findings shown in Figure 10 indicate minor variations between the age of the participants and the average score for all the conflict management styles, with the exception of compromise style. For the compromise style, there were differences between younger and older respondents, with increasing preference by the older participants. However, there was no statistical significance based on the one-way ANOVA analysis that was conducted, see Table 12. There were no statistically significant differences between Age and each of the CMS (F<Fcrit and Pvalue $>0.05)$. 


\section{Age vs overall CMS}

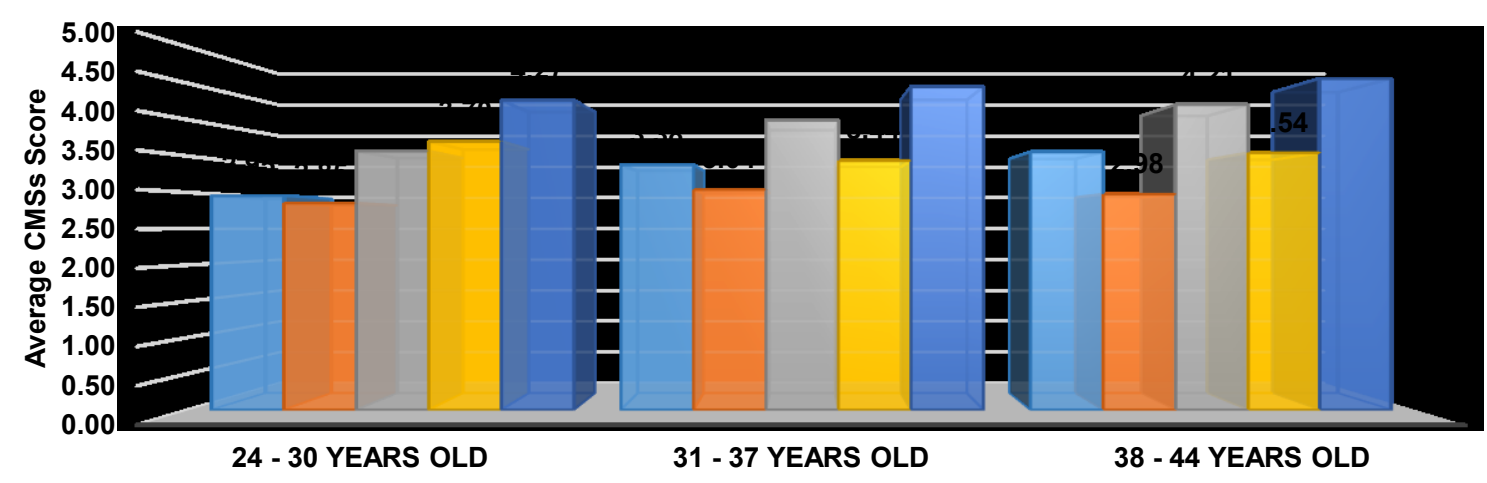

\begin{tabular}{|l|c|c|c|}
\cline { 2 - 4 } \multicolumn{1}{c|}{} & $24-30$ Years Old & $31-37$ Years Old & $38-44$ Years Old \\
\hline Avoidance & 2.95 & 3.38 & 3.56 \\
\hline Competition & 2.85 & 3.04 & 2.98 \\
\hline$\square$ Compromise & 3.57 & 3.99 & 4.21 \\
\hline Accommodation & 3.70 & 3.44 & 3.54 \\
\hline$\square$ Collaboration & 4.27 & 4.45 & 4.56 \\
\hline
\end{tabular}

Figure 10 - Age vs overall CMS

Table 12 - Age vs overall CMS Inferential Statistics

Variables

Age vs Avoidance

Between Groups

Within Groups

Total

Age vs Competition

Between Groups

Within Groups

Total

Age vs Compromise

Between Groups

Within Groups

Total

Age vs Accommodation

Between Groups

Within Groups

Total
SS df MS

$\begin{array}{lll}1.14 & 2 & 0.57\end{array}$

$22.42 \quad 46 \quad 0.49$

$23.56 \quad 48$

\section{Inferential Statistics}

F

P-value

F crit

$1.17 \quad 0.319$

3.20

SS df $\quad$ MS

MS

F

P-value F crit

$\begin{array}{llllll}0.16 & 2 & 0.08 & 0.12 & 0.889 & 3.20\end{array}$

$31.42 \quad 46 \quad 0.68$

$31.59 \quad 48$

\begin{tabular}{cccccc} 
SS & df & MS & F & P-value & F crit \\
\hline 1.26 & 2 & 0.63 & 1.87 & 0.166 & 3.20 \\
\hline 15.55 & 46 & 0.34 & & & \\
\hline
\end{tabular}

$16.81 \quad 48$

\begin{tabular}{cccccc} 
SS & df & MS & F & P-value & F crit \\
0.34 & 2 & 0.17 & 0.96 & 0.389 & 3.20 \\
8.17 & 46 & 0.18 & & & \\
\hline
\end{tabular}

$8.52 \quad 48$




\begin{tabular}{ccccccc} 
Age vs Collaboration & SS & df & MS & F & P-value & F crit \\
\hline Between Groups & 0.27 & 2 & 0.14 & 0.70 & 0.499 & 3.20 \\
\hline Within Groups & 8.90 & 46 & 0.19 & & & \\
\hline \hline Total & $\mathbf{9 . 1 7}$ & $\mathbf{4 8}$ & & & \\
& & & & P-value $<0.05$ Statistically Significant
\end{tabular}

\section{Work experience vs overall CMS}

The gender of the participants and the average score for avoidance, competition and accommodation styles indicate minimal variations (Figure 11), whilst compromise and collaboration styles had slightly higher difference between groups. The preference for compromise and collaboration styles was slightly lower for participants with work experience of 1-5 years and for the more experienced group of 12-17 years, while the participants with 611 years outperformed both age groups. The statistical significance was analysed using a oneway ANOVA and despite the difference between work experience, compromise and collaboration styles, the variance between groups was only significant for collaboration style (p-value 0.045) $(\mathrm{F}>$ Fcrit and $\mathrm{P}$-value $<0.05)$. The participants with 6 to 11 years of work experience demonstrated a higher preference for collaboration style.

\section{Work experience vs overall CMS}

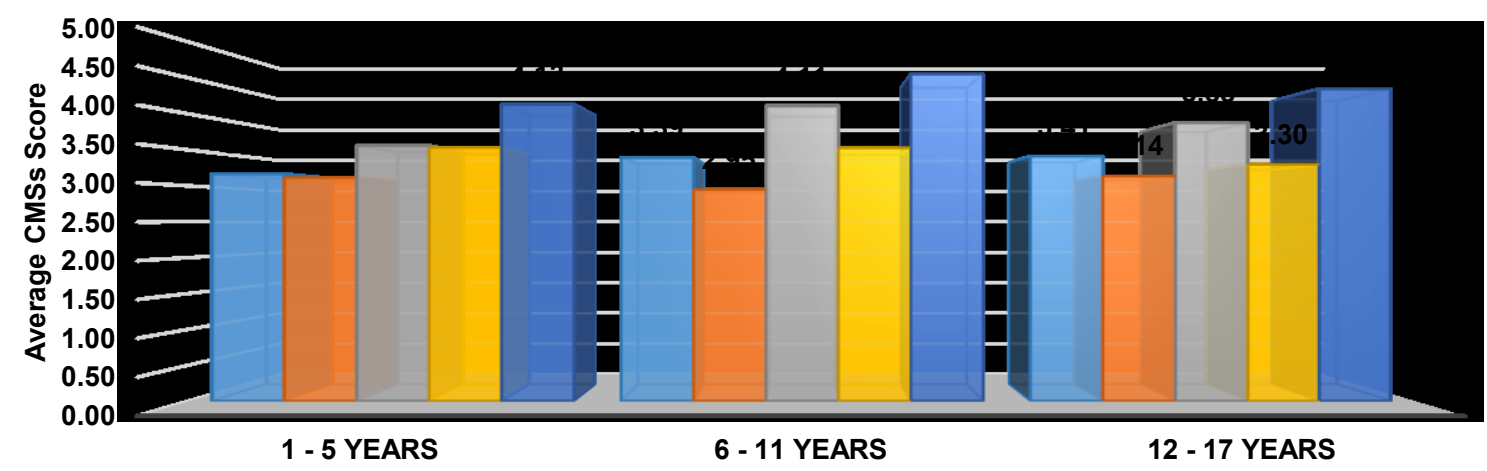

\begin{tabular}{|l|c|c|c|}
\cline { 2 - 4 } \multicolumn{1}{c|}{} & $1-5$ Years & $6-11$ Years & $12-17$ Years \\
\hline$\square$ Avoidance & 3.17 & 3.39 & 3.41 \\
\hline Competition & 3.11 & 2.95 & 3.14 \\
\hline$\square$ Compromise & 3.56 & 4.11 & 3.88 \\
\hline$\square$ Collaboration & 3.53 & 3.53 & 3.30 \\
\hline
\end{tabular}

Figure 11 - Work experience vs overall CMS

Table 13 - Work experience vs overall CMS Inferential Statistics

Variables

Work Experience vs Avoidance

Between Groups

Within Groups

SS
0.32
23.24

$2 \quad 0.16$

0.51

$\begin{array}{cccc}\text { MS } & \text { F } & \text { P-value } & \text { F crit } \\ 0.16 & 0.32 & 0.729 & 3.20 \\ 0.51 & & & \end{array}$

\begin{tabular}{cccc} 
MS & F & P-value & F crit \\
0.16 & 0.32 & 0.729 & 3.20 \\
\hline .51 & & &
\end{tabular}

\section{Inferential Statistics}




\begin{tabular}{|c|c|c|c|c|c|c|}
\hline Total & 23.56 & 48 & & & & \\
\hline Work Experience vs Competition & SS & df & MS & $\mathbf{F}$ & P-value & F crit \\
\hline Between Groups & 0.36 & 2 & 0.18 & 0.26 & 0.770 & 3.20 \\
\hline Within Groups & 31.23 & 46 & 0.68 & & & \\
\hline Total & 31.59 & 48 & & & & \\
\hline Work Experience vs Compromise & SS & df & MS & $\mathbf{F}$ & P-value & F crit \\
\hline Between Groups & 1.87 & 2 & 0.93 & 2.87 & 0.067 & 3.20 \\
\hline Within Groups & 14.94 & 46 & 0.32 & & & \\
\hline Total & 16.81 & 48 & & & & \\
\hline $\begin{array}{l}\text { Work Experience vs } \\
\text { Accommodation }\end{array}$ & SS & df & MS & $\mathbf{F}$ & P-value & $F$ crit \\
\hline Between Groups & 0.43 & 2 & 0.22 & 1.23 & 0.300 & 3.20 \\
\hline Within Groups & 8.08 & 46 & 0.18 & & & \\
\hline Total & 8.52 & 48 & & & & \\
\hline Work Experience vs Collaboration & SS & df & MS & $\mathbf{F}$ & P-value & F crit \\
\hline Between Groups & 1.16 & 2 & 0.58 & 3.32 & 0.045 & 3.20 \\
\hline Within Groups & 8.02 & 46 & 0.17 & 0.00 & & \\
\hline Total & 9.17 & 48 & & & & \\
\hline
\end{tabular}

\section{EIL vs CMS}

The relationship between emotional intelligence levels (EIL) and conflict management styles (CMS) show the score for each of the EI dimensions including the total EI linked with each score of the overall CMS to deduce a correlation matrix. The inferential statistics for a twotailed test was used to determine the direction, magnitude, and significance of the correlation between these variables using the Pearson's correlation coefficient (r) and the probability value (p).

\section{Correlation Matrix}

The correlation matrix between the independent variables (emotional intelligence dimensions) and the dependent variables (overall conflict management styles) presented in Table 14 suggest that there is a statistically significant correlation between self-awareness and collaboration style $(p<0.01)$ with a moderate positive correlation between the two variables $(r=0.498)$. Similarly, the relationship between self-management and collaboration style is equally statistically significant $(\mathrm{p}<0.01)$ with a moderate positive correlation $(\mathrm{r}=0.418)$. This means that participants with higher EIL for self-awareness and self-management tend to prefer more of the collaboration style. Unlike the previous EI dimensions, Social Awareness resulted in statistically significant relationships with more than one dependent variable, i.e., with avoidance $(\mathrm{p}<0.05)$ and collaboration $(\mathrm{p}<0.01)$. With these two dependent variables, a positive correlation was found to be low $(\mathrm{r}=0.358)$ and moderate $(\mathrm{r}=0.529)$ respectively. 
For relationship management and total EI, there was also a correlation with two conflict management styles. The relationship management with compromise and collaboration styles were significantly related $(\mathrm{p}<0.01)$. Relationship management was positively correlated with compromise and collaboration with a moderate and high magnitude respectively $(\mathrm{r}=0.421$ and $r=0.624)$. Similarly, the total EI statistically significantly correlated with compromise and collaboration styles $(\mathrm{p}<0.05$ and $\mathrm{p}<0.01)$, indicating a low positive correlation with compromise style $(\mathrm{r}=0.328)$ and a high positive correlation with collaboration style $(\mathrm{r}=$ $0.645)$.

Table 14 - EI Scores vs CMSs Scores Overall

\begin{tabular}{|c|c|c|c|c|c|c|c|c|c|c|}
\hline \multicolumn{11}{|c|}{ Inferential Statistics } \\
\hline \multirow{3}{*}{$\begin{array}{c}\text { Emotional Intelligence } \\
\text { Dimensions }\end{array}$} & \multicolumn{10}{|c|}{ Conflict Management Styles Overall } \\
\hline & \multicolumn{2}{|c|}{ Avoidance } & \multicolumn{2}{|c|}{ Competition } & \multicolumn{2}{|c|}{ Compromise } & \multicolumn{2}{|c|}{ Accommodation } & \multicolumn{2}{|c|}{ Collaboration } \\
\hline & $\mathbf{r}$ & $\mathbf{p}$ & $\mathbf{r}$ & $\mathbf{p}$ & $\mathbf{r}$ & $\mathbf{p}$ & $\mathbf{r}$ & $\mathbf{p}$ & $\mathbf{r}$ & $\mathbf{p}$ \\
\hline Self-Awareness & 0.174 & 0.232 & -0.046 & 0.751 & 0.125 & 0.391 & -0.147 & 0.313 & 0.498 & 0.0003 \\
\hline Self-Management & 0.036 & 0.808 & -0.131 & 0.370 & 0.256 & 0.076 & -0.081 & 0.580 & 0.418 & 0.003 \\
\hline Social Awareness & 0.358 & 0.011 & -0.140 & 0.337 & 0.253 & 0.080 & 0.266 & 0.064 & 0.529 & 0.0001 \\
\hline Relationship Management & 0.152 & 0.298 & 0.053 & 0.719 & 0.421 & 0.003 & 0.102 & 0.483 & 0.624 & 0.000002 \\
\hline Total EI & 0.237 & 0.101 & -0.076 & 0.603 & 0.328 & 0.021 & 0.062 & 0.673 & 0.645 & 0.000001 \\
\hline \multicolumn{11}{|l|}{$\mathrm{p}<0.05$ Statistically Significant } \\
\hline $\mathrm{p}<0.01$ Statistically Significant & & & & & & & & & & \\
\hline
\end{tabular}

\section{Discussion}

The profile of the participants had more males than females; most of the participants were between the age of 31 to 37 years; and with 6 to 11 years of work experience. The gender disparity was mainly due to the number of registered female Civil Engineers in CODIA $(\mathrm{N}=4,246)$ compared to males $(\mathrm{N}=15,303)$ (CODIA, 2020). This disparity reflects the fact that the construction industry is still male-dominated like in many other countries, with assumed social stereotype (Srivishagan \& Thalpage, 2019). Furthermore, participants within this age bracket are within the active working age, thus ultimately shaping the years of work experience. The findings revealed that the most common levels of emotional intelligence (RQ1) amongst Civil Engineers in the Dominican Republic's construction industry was high to moderate levels of EI which supports the first hypothesis. The ranking of the EI dimensions with the highest average scores was self-awareness, relationship management, social awareness, and selfmanagement, with a total EI score of 78. This result is consistent with the TalentSmart (2010) average EI score of 75 on a 100-point scale obtained by individuals who took the EIA test across different industries and professions. Existing study indicates that construction project workers with higher emotional intelligence tend to display higher satisfaction, greater commitment towards their job, and lower turnover intentions in relation to their roles (Rezvani, et al., 2020)

The most preferred conflict management styles by the participants (RQ2) were collaboration and compromise styles which supports the second hypothesis. These findings are consistent 
with studies conducted by Lee (2008); Al-Sedairy (1994); and Özkalp, et al. (2009); and partially with those of Gunarathna, et al. (2018) and Ogunbayo, (2013). Although the findings indicate that collaboration and compromise were the most preferred styles, the other CMS were also favourably preferred by most participants. This suggests that each style of conflict management can be strongly associated with the participants, supporting the statement that each style is adaptable to fit a specific situation (Sunindijo \& Hadikusumo, 2014). Maiti \& Choi (2021) also suggested that organisational performance shows a positive relationship with conflict management strategies such as compromise, collective bargaining and accommodation. Based on the one-way ANOVA analysis, there was no significant relationship between emotional intelligence scores and demographic variables (RQ3) indicating that the third hypothesis was not supported by this study. Chinyamurindi \& Marembo (2018) and Ahmad \& Zadeh (2016) also found no major differences in EI levels based on any or all of these three respondent demographics. However, findings from this study tend to contradict the generally accepted hypothesis that females are more emotionally intelligent than males and that emotional intelligence levels increase with age and work experience (Bar-On, 1997; Mayer, et al., 1999; Petrides, et al., 2004).

The one-way ANOVA analysis indicated a significant relationship between overall CMS (i.e. dealing with superiors, subordinates, and peers) and gender, as well as the relationship between overall CMS and years of work experience (RQ4). However, there was no significant relationship in terms of age which is consistent with Antonioni's (1998) empirical study. Therefore, the fourth hypothesis is only partially supported by this study. The findings regarding gender revealed that females presented higher preference towards collaboration styles than males. This further support the study conducted by Rosenthal \& Hautaluoma (1988) where they found that women preferred more collaboration styles. The results reported in this study found that participants with 6 to 11 years of professional work experience presented higher preference towards collaboration style compared to other work experience groups. This result is different from Abbas \& Karage (2015) who found that Indian employees exhibit a less collaborative and more competitive approach towards resolving conflict as their professional work experience increased. Despite the statistical significance of the relationship between some variables with collaboration style, this study suggests that rather than demographic characteristics being the precursor for collaboration style, the influencing factor could be the collectivist culture of the Dominican Republic (Hofstede Insights, 2020; Gunkel, et al., 2016).

The Pearson's correlation coefficient and probability value (RQ5) indicates statistically significant relationships across all EI dimensions including the total EI for at least one of the conflict management styles. The directions for all correlations were positive, meaning that an increment in the independent variable results in an increase in the dependent variable(s). Participants with higher levels of self-awareness and self-management tend to prefer more collaboration than other styles of $\mathrm{CM}$ with a moderate correlation magnitude. On the other hand, participants with higher levels of social awareness preferred more collaboration and avoidance styles, with a weak and moderate correlation magnitude respectively. The participants with higher levels of relationship management preferred more collaboration and compromise styles, including those with higher levels of total EI. Both relationship management and total EI resulted in a strong magnitude correlation with collaboration and compromise CM styles. The fifth hypothesis did not absolutely match the results, suggesting that the hypothesis was only partially supported by this study. This study however resonates 
with Sunindijo and Hadikusumo (2014), revealing that construction professionals with high EI feel comfortable in using collaboration style influenced by their collectivist culture. It is also partially consistent with Chen, et al. (2019) indicating that when the level of relationship management alone is high, compromise style becomes the preferred conflict management styles with peers, superiors, and subordinates. This study thus supports the perception that individuals with higher levels of EI lean towards collaboration and compromise styles because both styles are widely considered to result in functional outcomes (Gross \& Guerrero, 2000; Jordan \& Troth, 2004) and Montenegro, et al., (2021) showed that some components of emotional intelligence of construction project managers significantly influences the project success and stakeholder relationships.

\section{Conclusion}

This study explored the impact of emotional intelligence levels and demographic factors on the preferred conflict management styles adopted by Civil Engineers in the construction industry of the Dominican Republic. The study concludes that the average EI score for the Civil Engineers that participated in the Emotional Intelligence Appraisal (EIA) test was 78 on a 100point scale. Majority of the participants exhibited high to moderate levels of emotional intelligence, and no significant relationship was found between emotional intelligence scores and any of the demographic variables. The most dominant conflict management styles in order of hierarchical preference were collaboration and compromise, followed by accommodation, avoidance, and competition styles. There was significant relationship between CMS, gender, and years of work experience when participants were assessed in terms of dealing with their superiors, subordinates, and peers but no significant relationship was found with age. Regarding gender and work experience, the female participants with 6 to 11 years of professional experience demonstrated higher preference for collaboration style than males and with the other groups of participants with 1-5 and 12-17 years of work experience. The study concludes that collaboration style was however the most highly preferred style when compared with all the demographic variables and groups regardless of the statistical significance. This suggests that the preference for collaboration style could most likely have been influenced by the collectivist culture of the Dominican Republic that emphasizes the needs and goals of the group as a whole over the needs and desires of each individual as opposed to the demographic characteristics influencing the collaboration style.

The participants with higher levels of self-awareness and self-management preferred more collaboration than other styles, while participants with higher levels of social awareness preferred more collaboration and avoidance styles. However, participants with higher levels of relationship management and the total EI preferred more collaboration and compromise styles. This might be influenced by the extensive claims that collaboration and compromise are more appropriate to producing constructive outcomes. It is these constructive outcomes that influences individuals with higher levels of EI to lean towards collaboration and compromise styles when managing conflicts within the construction industry.

This study contributes to existing findings regarding the correlation between emotional intelligence levels, conflict management styles, and demographic variables such as gender, age and work experience but within the domain of the Dominican Republic. Although the study infer that cultural factors could have influenced the conflict management styles adopted by construction managers; enlightening them on issues of emotional intelligence could also 
enhance their abilities to adequately manage conflicts in the workplace. Whilst the five conflict management styles could be helpful depending on the situation and task, adopting the wrong conflict management style could be detrimental to the successful working relationships and the safe delivery of projects within a team or organisation. Therefore, having an understanding of the conflict management style that may be more effective to produce a desirable outcome in a specific situation would be beneficial for all parties involved towards improving team cohesion, workforce engagement, wellbeing, productivity and site safety.

\section{Implications}

This study has important implications for construction management in the Dominican Republic. It is the first in this context to look at the correlation between emotional intelligence levels, conflict management styles and demographic factors in the Dominican Republic construction sector. The findings offer some insight regarding human resource management process during recruitment, selection and promotion, with the knowledge that appropriate combination of employee demographics within the workplace can potentially contribute to effective organisational conflict management. Construction managers who employ the emotional intelligence competencies in the work environment could serve as a mentor for their subordinates regarding how to manage their emotions and resolve daily work conflicts. Furthermore, construction can prioritise hiring innovative and competent construction managers whose conflict management styles and emotional intelligence levels are compatible with the organisational culture and overall safety objectives. The relationship between emotional intelligence levels and conflict management styles should be recognised by construction and project managers and they should be aware of their own emotions and that of others towards managing conflicts effectively. This suggests that construction and project managers should be able to handle conflicts using different conflict management styles dependent on the circumstances and cultural beliefs rather than adopting a one-size fits all approach. This study contributes to the understanding of the issues of emotional intelligence and conflict management within the construction industry of the Dominican Republic. The findings are significant in term of adding some context to existing literature, expanding the knowledge and stimulating more research towards improving the effectiveness of managing the relationships between the different duty holders involved in managing construction projects.

\section{References}

Abbas, S. S. M. \& Karage, A. I., 2015 . Workplace Conflict Management Styles:

Comparative Study of Indian and Nigerian Employees. European Journal of Business and Management, 7(23), pp. 44-54.

Ahmad, S. M. \& Zadeh, Z F., 2016. Gender Differences on the Variables of Emotional Intelligence, Creative-Potential and Job Satisfaction in Managers. Pakistan Journal of Psychology, 47(2).

Akiner, I., 2014. Critical Viewpoints on the Management of Conflict in Multi-National Construction Projects. Organization, Technology \& Management in Construction, 6(2), pp. 1038-1046.

Al-Sedairy, S. T., 1994. Management of Conflict: Public-Sector Construction in Saudi Arabia. International Journal of Project Management, 12(3), pp. 143-151. 
Antonioni, D., 1998. Relationship between the Big Five Personality Factors and Conflict Management Styles. International Journal of Conflict Management, 9(4), pp. 336-355.

Barbuto, J. E., Phipps, K. A. \& Xu, Y., 2010. Testing Relationships between Personality, Conflict Styles and Effectiveness. International Journal of Conflict Management, 21(4), pp. 434-447.

Bar-On, R., 1997. The Emotional Quotient Inventory (EQ-i): Technical Manual. Toronto: Multi-health Systems.

Bar-On, R. \& Parker, J. D. A., 2000. Handbook of Emotional Intelligence: Theory, Development, Assessment, and Application at Home, School, and in the Workplace. San Francisco: Jossey-Bass.

Ben-Yoav, O. \& Banai, M., 1992. Measuring Conflict Management Styles: A Comparison Between the Mode and ROCI-II Instruments Using Self and Peers Rating. International Journal of Conflict Management, 3(3), pp. 237-247.

Blaikie, N. W. H. \& Priest, J., 2019. Designing Social Research: The Logic of Anticipation. 3rd ed. Cambridge ;: Polity Press.

Bollen, K., Euwema, M. \& Munduate, L., 2016. Advancing Workplace Mediation Through Integration of Theory and Practice. 1st ed. 2016. [Online]. Cham: Springer International Publishing.

Bradberry, T. \& Greaves, J., 2010. Emotional Intelligence Appraisal Technical Manual. San Diego: TalentSmart Inc..

Chandolia, E. \& Anastasiou, S., 2020. Leadership and Conflict Management Style Are Associated with the Effectiveness of School Conflict Management in the Region of Epirus, NW Greece. European Journal of Investigation in Health, Psychology and Education, 10(1), pp. 455-468. https://doi.org/10.3390/ejihpe10010034.

Chen, H. X., Xu, X. \& Phillips, P., 2019. Emotional Intelligence and Conflict Management Styles. International Journal of Organizational Analysis, 27(3), pp. 458-470.

Cherniss, C. \& Goleman, D. (2001) The emotionally intelligent workplace : how to select for measure, and improve emotional intelligence in individuals, groups, and organizations . 1st ed. San Francisco: Jossey-Bass.

Chinyamurindi, W. T. \& Marembo, M., 2018. Impact of Demographic Variables on Emotional Intelligence Levels Amongst a Sample of Early Career Academics at a South African Higher Education Institution. SA Journal of Human Resource Managemen, Volume 16, pp. 1-9.

CODIA, 2020. CODIA. [Online]

Available at: http://www.codia.org.do/transparencia/index.php/estadisticas [Accessed 1008 2020].

Côté, S., 2017. Enhancing managerial effectiveness via four core facets of emotional intelligence. Organizational Dynamics, 46(3), pp. 140-147. 
Côté, S. \& Miners, C. T. H., 2006. Emotional Intelligence, Cognitive Intelligence, and Job Performance. Administrative Science Quarterly, 51(1), pp. 1-28.

Daly, T. M., Anne Lee, J., Soutar, G. N. \& Rasmi, S., 2010. Conflict-Handling Style Measurement: A Best-Worst Scaling Application. International Journal of Conflict Management, 21(3), pp. 281-308.

Donnelly, R. A. \& Abdel-Raouf, F., 2016. Statistics. 3rd ed. First American edition. Indianapolis, Indiana: Alpha, a member of Penguin Random House LLC.

Elgoibar, P., Euwema, M. \& Munduate, L., 2016. Building Trust and Constructive Conflict Management in Organizations. 1st ed. Cham: Springer International Publishing.

Goleman, D., 2009a. Emotional Intelligence: Why It Can Matter More Than IQ. London: Bloomsbury. [[1995]]

Goleman, D., 2009b. Working With Emotional Intelligence. London: Bloomsbury Publishing.. [[1998]]

Goleman, D. et al., 2017. Emotional Self-Awareness: A Primer. 1st ed. Northampton: More Than Sound.

Gonçalves, G. et al., 2016. Cultural Intelligence and Conflict Management Styles. International Journal of Organizational Analysis, 24(4), pp. 725-742.

Gross, M. A. \& Guerrero, L. K., 2000. Managing Conflict Appropriately and Effectively: An Application of the Competence Model to Rahim's Organizational Conflict Styles. International Journal of Conflict Management, 11(3), pp. 200-226.

Gunarathna, C., Yang, R. J. \& Fernando, N., 2018. Conflicts and Management Styles in the Sri Lankan Commercial Building Sector. Engineering, Construction and Architectural Management, 25(2), pp. 178-201.

Gunkel, M., Schlaegel, C. \& Taras, V., 2016. Cultural Values, Emotional Intelligence, and Conflict Handling Styles: A Global Study. Journal of world business : JWB, 51(4), pp. 568585 .

Hasson, G. (2015) Understanding emotional intelligence. Rejacketed edition. Harlow, England: Pearson.

Hofstede Insights, 2020. Hofstede Insights. [Online]

Available at: https://www.hofstede-insights.com/country/the-dominican-

republic/\#: : :text=The $\% 20$ Dominican $\% 20$ Republic $\% 2 \mathrm{C} \% 20 \mathrm{with} \% 20 \mathrm{a}$,extended $\% 20$ family $\%$ 2C\%20or\%20extended $\% 20$ relationships.

[Accessed 1308 2020].

Ikpesu, O., 2017. Self - Management Dimension of Emotional Intelligence as Determination of Academic Administration in Public University. Journal of Higher Education Theory and Practice, 17(1), pp. 49-57. 
Jordan, P. J. \& Troth, A. C., 2002. Emotional Intelligence and Conflict Resolution: Implications for Human Resource Development. Advances in Developing Human Resources, 4(1), pp. 62-79.

Jordan, P. J. \& Troth, A. C., 2004. Managing Emotions During Team Problem Solving: Emotional Intelligence and Conflict Resolution. Human Performance, 17(2), pp. 195-218.

Kaifi, B. A. \& Noori, S. A., 2010. Organizational Management: A Study on Middle Managers, Gender, and Emotional Intelligence Levels. Journal of Business Studies Quarterly, 1(3), pp. 13-23.

Kessler, E. H., 2013. Encyclopedia of Management Theory. Los Angeles: SAGE Publications, Inc..

Khan, K., Hussainy, S. K. \& Iqbal, Y., 2016. Causes, Effects, and Remedies in Conflict Management. The South East Asian Journal of Management, 10(2), pp. 152-172.

Kukah, A.S., Akomea-Frimpong, I., Jin, X. \& Osei-Kyei, R., 2021. Emotional intelligence (EI) research in the construction industry: a review and future directions. Engineering, Construction and Architectural Management, Vol. ahead-of-print No. ahead-of-print. https://doi.org/10.1108/ECAM-05-2021-0414.

Lawani, A \& Moore, D. R., 2021. Propositions for utilising emotional intelligence in construction organisations. International Journal of Construction Management, 21(2), pp. 153-166. https://doi.org/10.1080/15623599.2018.1512028.

Lawani, K., Hare, B., \& Cameron I., 2019. Evaluating workplace trust as a construct of worker engagement in construction. Management, Procurement and Law, 172:3, 125-134

Lawani, K., Hare, B., Cameron, I. \& Soto, L. M. I., 2020. Exploring the Impact of Alcohol Abuse on Construction Sites in Santo Domingo, Dominican Republic In: Scott, L and Neilson, C J (Eds) Proceedings of the 36th Annual ARCOM Conference, 585-594

Lee, K. L., 2008. An Examination between the Relationships of Conflict Management Styles and Employees' Satisfaction. International Journal of Business and Management, 3(9), pp. 11-25.

Loosemore, M. \& Galea, N., 2008. Genderlect and Conflict in the Australian Construction Industry. Construction Management and Economics, 26(2), pp. 125-135.

Loosemore, M., Nguyen, B. T. \& Denis, N., 2000. An Investigation into the Merits of Encouraging Conflict in the Construction Industry. Construction Management and Economics, 18(4), pp. 447-456.

Love, P., Edwards, D. \& Wood, E., 2011. Loosening the Gordian Knot: The role of Emotional Intelligence in Construction. Engineering, Construction and Architectural Management, 18(1), pp. 50-65.

Maiti, Saikat \& Choi, Jae-ho., 2021. Investigation and implementation of conflict management strategies to minimize conflicts in the construction industry. International Journal of Construction Management, 21(4), pp. 337-352. https://doi.org/10.1080/15623599.2018.1536964. 
Manu, E., Ankrah, N., Chinyio, E. \& Proverbs, D., 2015. Trust influencing factors in main contractor and subcontractor relationships during projects. International Journal of Project Management, 33(7), pp. 1495-1508. https://doi.org/10.1016/j.ijproman.2015.06.006.

Mayer, J. D., Caruso, D. R. \& Salovey, P., 1999. Emotional Intelligence Meets Traditional Standards for an Intelligence. Intelligence, 27(4), pp. 267-298.

Mayer, J. D. \& Salovey, P., 1997. What is Emotional Intelligence?. In: P. Salovey \& D. Sluyter, eds. Emotional Development And Emotional Intelligence: Educational Implications. 1st ed. New York: Basic Books, pp. 3-31.

Meng, Xianhai., 2012. The effect of relationship management on project performance in construction. International Journal of Project Management, 30(2), pp. 188-198. https://doi.org/10.1016/j.ijproman.2011.04.002.

Mo, Y. Y. \& Dainty, A. R. J., 2007. Measuring and Enhancing the Emotional Intelligence of Construction Management Students: An Empirical Investigation. Journal for Education in the Built Environment, 2(1), pp. 110-129, DOI: 10.11120/jebe.2007.02010110.

Moberg, P. J., 2001. Linking Conflict Strategy to the Five-Factor Model: Theoretical and Empirical Foundations. International Journal of Conflict Management, 12(1), pp. 47-68.

Montenegro, A., Dobrota, M., Todorovic, M., Slavinski, T. \& Obradovic, V., 2021. Impact of Construction Project Managers' Emotional Intelligence on Project Success. Sustainability, 13(19),10804. https://doi.org/10.3390/su131910804.

Moradi, S., Kähkönen, K. \& Aaltonen, K., 2020. Project Managers' Competencies in Collaborative Construction Projects. Buildings, 10(3):50.

https://doi.org/10.3390/buildings10030050.

Northouse, P. G., 2018. Introduction to Leadership: Concepts and Practice. 4th ed. Los Angeles: SAGE Publications.

Ofori, G., 2013. Conflict in Construction. Construction Management and Economics, 31(5), p. 497-501.

Ogunbayo, O., 2013. Conflict Management in Nigerian Construction Industry: Project Managers' View. Journal of Emerging Trends in Economics and Management Sciences, 4(2), pp. 140-146.

Özkalp, E., Sungur, Z. \& Ay E Özdemir, A., 2009. Conflict Management Styles of Turkish Managers. Journal of European Industrial Training, 33(5), pp. 419-438.

Petrides, K. V. \& Furnham, A., 2000. On the Dimensional Structure of Emotional Intelligence. Personality and Individual Differences, 29(2), pp. 313-320.

Petrides, K. V., Furnham, A. \& Martin, G. N., 2004. Estimates of Emotional and Psychometric Intelligence: Evidence for Gender-Based Stereotypes. The Journal of Social Psychology, 144(2), pp. 149-162.

Proksch, S., 2016. Conflict Management. 1st ed. Cham: Springer International Publishing AG. 
Pryke, S., Lunic, D. \& Badi, S., 2015. The Effect of Leader Emotional Intelligence on Leader-Follower Chemistry: a Study of Construction Project Managers. Construction Management and Economics, 33(8), pp. 603-624.

Rahim, M. A., 1983a. A Measure of Styles of Handling Interpersonal Conflict. The Academy of Management Journal, 26(2), pp. 368-376.

Rahim, M. A., 1983b. Rahim Organizational Conflict Inventories: Professional Manual. Palo Alto: Consulting Psychology Press.

Rahim, M. A., 2002. Toward a Theory of Managing Organizational Conflict. International Journal of Conflict Management, 13(3), pp. 206-235.

Rahim, M. A., Antonioni, D. \& Psenicka, C., 2001. A Structural Equations Model of Leader Power, Subordinates' Styles of Handling Conflict, and Job Performance. International Journal of Conflict Management, 12(3), pp. 191-211.

Randeree, K. \& Faramawy, A. T. E., 2011. Islamic Perspectives on Conflict Management Within Project Managed Environments. International Journal of Project Management, 29(1), pp. 26-32.

Rezvani, A., Ashkanasy, N. \& Khosravi, P., 2020. Key Attitudes: Unlocking the Relationships between Emotional Intelligence and Performance in Construction Projects. Journal of Construction Engineering and Management, 146(4), 04020025 https://doi.org/10.1061/(ASCE)CO.1943-7862.0001803.

Rhoden, M., 2016. Construction Management and Organisational Behaviour. Somerset: John Wiley \& Sons, Inc..

Robbins, S. P. \& Coulter, M. K., 2016. Management. 13th ed. Global edition. Harlow: Pearson.

Rosenthal, D. B. \& Hautaluoma, J., 1988. Effects of Importance of Issues, Gender, and Power of Contenders on Conflict Management Style. Journal of Social Psychology, Volume 128 (5), pp. 699-701.

Runde, C. E. \& Flanagan, T. A., 2010. Developing Your Conflict Competence: A Hands-On Guide for Leaders, Managers, Facilitators, and Teams. 1st ed. Hoboken: Wiley.

Saini, A. \& Soni, N., 2016. Role of Emotional Intelligence in Construction Industry: A Review. International Journal of Civil Engineering and Technology (IJCIET), 7(4), pp. 339344.

Salkind, N. J., 2010. Encyclopedia of Research Design. 3rd ed. Thousand Oaks: SAGE Publications.

Salovey, P. \& Mayer, J. D., 1990. Emotional Intelligence. Imagination, Cognition and Personality, 9(3), pp. 185-211.

Saunders, M. N. K., Lewis, P. \& Thornhill, A., 2019. Research Methods for Business Students. 8th ed. New York: Pearson. 
Sears, S. K., 2015. Construction Project Management: A Practical Guide to Field Construction Management. 6th ed. New Jersey: Hoboken.

Shih, H.-A. \& Susanto, E., 2010. Conflict Management Styles, Emotional Intelligence, and Job Performance in Public Organizations. International Journal of Conflict Management, 21(2), pp. 147-168.

Siegling, A. B., Sfeir, M. \& Smyth, H. J., 2014. Measured and Self-Estimated Trait Emotional Intelligence in a UK Sample of Managers. Personality and Individual Differences, Volume 65, pp. 6559-64.

Spaho, K., 2013. Organizational Communication and Conflict Management. Management : Journal of Contemporary Management Issues, 18(1), pp. 103-118.

Srivishagan, V. \& Thalpage, R., 2019. An Insight to Women in Construction for Fostering Female Careers in Sri Lankan Construction Industry. Journal of International Women's Studies, 20(3), pp. 168-173.

Subramoniam, S., 2004. Conflicts: Types, Causes And Resolution Strategies. Paradigm (Ghāziabād, India), 8(1), pp. 55-62.

Sunindijo, R. Y. \& Hadikusumo, B. H. W., 2014. Emotional Intelligence for Managing Conflicts in the Sociocultural Norms of the Thai Construction Industry. Journal of Management in Engineering, 30(6), 4014025-.

Sunindijo, R.Y. \& Maghrebi, M., 2020. Political Skill Improves the Effectiveness of Emotional Intelligence: Bayesian Network Analysis in the Construction Industry. Journal of Architectural Engineering, 26(3), 04020019. https://doi.org/10.1061/(ASCE)AE.1943$\underline{5568.0000417 .}$

TalentSmart, 2010. TalentSmart. [Online]

Available at: https://www.talentsmart.com/articles/How-Do-You-Stack-Up--EQ-Trends-byIndustry-41897549-p-

1.html\#: :text=It's\%20their\%20EQ\%20skills\%2C\%20not,on $\% 20 \mathrm{a} \% 20100 \% 2 \mathrm{Dpoint} \% 20$ sca le. [Accessed 0807 2020].

TalentSmart, 2020. TalentSmart. [Online]

Available at: https://www.talentsmart.com/products/

[Accessed 1407 2020].

Tsai, J. -S. \& Chi, C. S. F., 2009. Influences of Chinese Cultural Orientations and Conflict Management Styles on Construction Dispute Resolving Strategies. Journal of Construction Engineering and Management, 135(10), pp. 955-964.

Torubelli, V. \& Adeoye, H., 2011. Emotional Intelligence and Human Relationship Management As Predictors of Organisational Commitment. Ife Psychologia, 19(2), pp. 212226.

Van Rooy, D. L., Alonso, A. \& Viswesvaran, C., 2005. Group Differences in Emotional Intelligence Scores: Theoretical and Practical Implications. Personality and Individual Differences, 38(3), pp. 689-700. 
Vaux, J. S. \& Kirk, W. M., 2018. Relationship Conflict in Construction Management: Performance and Productivity Problem. Journal of Construction Engineering and Management, 144(6), 4018032-.

Vu, A. T. \& Carmichael, D. G., 2009. Cultural Difference and Conflict Management - A Vietnamese-Australian and Construction Industry Case Study. International Journal of Construction Management, 9(2), pp. 1-19.

Wang, T., Wu, J., Gu, J. \& Hu, L., 2021. Impact of open innovation on organizational performance in different conflict management styles: based on resource dependence theory. International Journal of Conflict Management, 32(2), pp. 199-222. https://doi.org/10.1108/IJCMA-09-2019-0165.

Whitfield, J., 2012. Conflicts in Construction. 2nd ed. Hoboken, N.J: Wiley-Blackwell.

Wu, G., Zhao, X. \& Zuo, J., 2017. Effects of Inter-Organizational Conflicts on Construction Project Added Value in China. International Journal of Conflict Management, 28(5), pp. 695-723. 